\title{
Chronic exercise training attenuates prostate cancer-induced molecular remodelling in the testis
}

Bárbara Matos' ${ }^{1}$, Daniela Patrício ${ }^{1}$, Magda C. Henriques ${ }^{1}$, Maria J. Freitas ${ }^{1}$, Rui Vitorino ${ }^{1}$, Iola F. Duarte $^{2}$, John Howl $^{3}$, Paula Oliveira ${ }^{4}$, Fernanda Seixas ${ }^{5}$ José A. Duarte $^{6}$, Rita Ferreira ${ }^{7}$, Margarida Fardilha $^{1}$

${ }^{1}$ Signal Transduction Laboratory, Institute of Biomedicine - iBiMED, Department of Medical Sciences, University of Aveiro, 3810-193 Aveiro, Portugal

${ }^{2}$ CICECO - Aveiro Institute of Materials, Department of Chemistry, University of Aveiro, Campus Universitário de Santiago, 3810-193 Aveiro, Portugal

${ }^{3}$ Molecular Pharmacology Group, Research Institute in Healthcare Science, University of Wolverhampton, WV1 1LY, UK

${ }^{4}$ CITAB, Department of Veterinary Sciences, University of Trás-os-Montes and Alto Douro, Vila Real, Portugal

${ }^{5}$ CECAV, Department of Veterinary Sciences, University of Trás-os-Montes and Alto Douro, Vila Real, Portugal

${ }^{6}$ CIAFEL, Faculty of Sport, University of Porto, Porto, Portugal

${ }^{7}$ QOPNA \& LAQV-REQUIMTE, Department of Chemistry, University of Aveiro, Campus Universitário de Santiago, 3810-193 Aveiro, Portugal

\section{Corresponding author}

Margarida Fardilha

e-mail: mfardilha@ua.pt

Tel.: +351234247240

ORCID: 0000-0001-7459-9173 


\begin{abstract}
Purpose Prostate cancer is a major cause of cancer-related death in males worldwide and, in addition to impairing prostate function, also causes testicular adaptations. In this study, we aim to investigate the preventive effect of exercise training on PCa-induced testicular dysfunction.

Methods As a model, we used fifty Wistar Unilever male rats, randomly divided in four experimental groups. Prostate cancer was chemically and hormonally induced in two groups of animals (PCa groups). One control group and one PCa group was submitted to moderate intensity treadmill exercise training. Fifty weeks after the start of the training the animals were sacrificed and sperm, prostate, testes and serum were collected and analyzed. Sperm concentration and morphology, and testosterone serum levels were determined. In addition, histological analysis of the testes was performed, and testis proteomes and metabolomes were characterized.

Results We found that prostate cancer negatively affected testicular function, manifested as an arrest of spermatogenesis. Oxidative stress-induced DNA damage, arising from reduced testis blood flow, may also contribute to apoptosis of germ cells and consequential spermatogenic impairment. Decreased utilization of the glycolytic pathway, increased metabolism of ketone bodies and the accumulation of branched chain amino acids were also evident in the PCa animals. Conversely, we found that the treadmill training regimen activated DNA repair mechanisms and counteracted several metabolic alterations caused by PCa without impact on oxidative stress.
\end{abstract}

Conclusions These findings confirm a negative impact of prostate cancer on testis function and suggest a beneficial role for exercise training in the prevention of prostate cancer-induced testis dysfunction.

Keywords: Prostate cancer, exercise training, testicular function, oxidative stress, DNA repair, metabolism 


\section{Introduction}

Prostate cancer $(\mathrm{PCa})$ is the second most common type of cancer diagnosed in men worldwide. A total of 1.28 million new cases of PCa were reported in 2018 and over 350000 patients died of this disease [1]. Accumulating evidence suggests an association between PCa and testicular dysfunction. Indeed, reduced sperm count and testosterone serum levels have been reported in PCa patients [2-4]. As yet, however, the mechanisms responsible for this negative effect are poorly understood. In addition to the reduced fertility rates of PCa patients who suffer from testicular dysfunction, decreased levels of testosterone seemingly correlate with the development of serious diseases including type 2 diabetes and cardiovascular pathologies [5,6]. Hence, the high incidence and lethality of PCa along with its associated comorbidities warrant the development of both preventive and therapeutic strategies as pressing medical needs.

Exercise training (EX) has been widely prescribed for its potential preventive and therapeutic effect towards PCa [7-11]. Although the subject remains controversial [12-15], several authors have reported a reduced proliferation and increased apoptosis of cancer cells in PCa patients undergoing EX [16-18]. A decrease in the serum levels of both insulin and vasoactive intestinal peptide (VIP), along with alterations in hormonal profiles, were the main mechanisms proposed to explain this response. The influence of EX on testis function also depends upon the type and intensity of the EX program. While high-intensity EX was found to be associated with reduced luteinizing hormone ( $\mathrm{LH}$ ), follicle-stimulating hormone (FSH), testosterone and semen parameters, for moderate-intensity EX there was no consensus among the published studies [19-22]. In subjects with testicular functional impairment caused by aging, obesity or drug treatment, EX was reported to prevent or counteract the decrease in testosterone serum levels and sperm counts [23-25]. Decreased oxidative stress and inflammation after EX were the mechanisms proposed to explain these findings [23,25]. Considering the existing evidence for beneficial effects of EX on both PCa and testis function, assessed independently, we hypothesized that EX may exert a protective effect on the testis of PCa subjects.

To test this hypothesis, we employed an animal model of chemically- and hormonally-induced PCa to characterize testicular adaptations induced by $\mathrm{PCa}$ and/or EX. Testis tissues from different groups (sedentary and exercised controls; sedentary and exercised PCa animals) were examined for changes in morphology, functional parameters and proteomic and metabolomic profiles. The ultimate goal of these comparative studies was to add novel molecular insights into the impact of EX on testicular function of PCa subjects.

\section{Material and methods}

\subsection{Animals}

A total of 50 Wistar Unilever male rats aged four weeks old were acquired from Charles River Laboratories (France). All animals were subjected to quarantine for two weeks and then randomly distributed over polycarbonate cages (five per cage). The cohort was then randomly divided into four experimental groups: Sedentary $(C O N T+S E D, n=9)$, Sedentary with PCa induction $(P C a+S E D, n=14)$, Exercised $(C O N T+E X, n$ 
$=10)$ and Exercised with PCa induction $(\mathrm{PCa}+\mathrm{EX}, \mathrm{n}=17)$. All were maintained in the animal facilities of the University of Trás-os-Montes and Alto Douro (UTAD) under controlled conditions, including a temperature of $22 \pm 2^{\circ} \mathrm{C}$, a $12 \mathrm{~h} \mathrm{light/dark} \mathrm{cycle} \mathrm{and} \mathrm{a} \mathrm{relative} \mathrm{humidity} \mathrm{of} 50 \pm 10 \%$. Animals were allowed to access food and water ad libitum (Mucedola 4RF21®, Milan, Italy). The experimental protocol was approved by the animal well-being responsible organ of UTAD and by Direção Geral de Alimentação e Veterinária-DGAV (license ${ }^{\circ}$ 021326).

\subsection{PCa induction}

In order to induce prostate lesions to PCa groups, the animals (aged twelve weeks old) received a subcutaneous administration of the anti-androgenic drug flutamide $(20 \mathrm{mg} / \mathrm{Kg}$; TCI Chemicals, Portland, OR, USA) for 21 consecutive days. After 24 hours, testosterone propionate (TCI Chemicals, Portland, OR, USA) was injected subcutaneously. N-methyl-nitrosourea (MNU, $30 \mathrm{mg} / \mathrm{Kg}$ prepared in citrate buffer $0.1 \mathrm{M} \mathrm{pH} 4.8$ ) was administered intraperitoneally 2 days later, and after 15 days, subcutaneous implants of crystallin testosterone (Sigma) were inserted in the interscapular region through a small incision followed by suture. This procedure was carried out under anesthesia ( $90 \mathrm{mg} / \mathrm{Kg}$ of ketamine and $9 \mathrm{mg} / \mathrm{Kg}$ of xylazine) and the implants (Dow Corning) were prepared in medical silicone tubes $(3.5 \mathrm{~cm})$ filled with testosterone and with the extremities sealed with medical glue (G.E. RTV-108).

\subsection{Endurance training protocol}

The animals of exercised groups (CONT+EX and PCa+EX) started the exercise program in a treadmill at the age of eight weeks (Treadmill Control LE 8710, Harvard Apparatus, USA), and this program was maintained for 50 weeks ( 5 days per week). The exercise program started with 30 min per day during the first week (habituation period) and was then increased to $60 \mathrm{~min}$ per day for the duration of the regimen. The speed of the treadmill was set to $70 \%$ of the maximal speed capacity of the animals with PCa and, every 6 weeks, the speed capacity was re-evaluated to correct for exercise intensity. The rodents were motivated to run on the treadmill by mild electrical shock stimulation. All animals from the EX groups completed the training program. In order to submit the sedentary animals to a similar stress, rats were regularly placed on a stationary treadmill for a few minutes.

\subsection{Samples collection}

The animals were euthanized by an overdose of anesthetics (a mixture of ketamine and xylazine), administered intraperitoneally, followed by exsanguination through cardiac puncture. The animals' weights were measured and blood, prostate, testes and epidydimal sperm were collected. Blood was centrifuged for $5 \mathrm{~min}$ at $5000 \mathrm{~g}$ after which serum was separated and stored at $-80^{\circ} \mathrm{C}$ for biochemical determinations. The prostates were weighed and immediately processed for anatomopathological analysis. In brief, prostate sections were fixed in $10 \%$ buffered formalin and processed to light microscopy according routine histological procedures. Hematoxylin and Eosin stained slides were evaluated at two different moments, in a blinded fashion, by an experienced pathologist. Lesions were classified according the cellular atypia, proliferation and invasive 
behavior, as normal (non-neoplastic prostate, reactive atypia associated to acute and chronic inflammation) or pre-neoplastic and neoplastic. The testes were weighed and immediately processed for histological analysis or stored at $-80^{\circ} \mathrm{C}$ for further biochemical analyses.

\subsection{Determination of testosterone serum levels}

Testosterone levels were determined in serum aliquots using a testosterone ELISA kit (Caymann Chemical, Ann Arbor, MI. USA). This kit assay is based upon competition between testosterone and a testosteroneacetylcholinesterase conjugate, with a concentration range from 3.9 to $500 \mathrm{pg} / \mathrm{ml}$ and a sensitivity of approximately $6 \mathrm{pg} / \mathrm{ml}$. According to the manufacturers' instructions, eight standards with decreasing testosterone concentrations were prepared, after which the absorbance at $412 \mathrm{~nm}$ was recorded using a microplate reader (Tecan® Infinite M200) and a standard curve was generated. The serum samples were diluted and, based on the standard curve, the testosterone concentrations were determined in $\mathrm{pg} / \mathrm{ml}$.

\subsection{Semen analysis}

Sperm concentrations were determined using a Neubauer chamber. The results were expressed as the number of spermatozoa $\times 106$ per $\mathrm{ml}$. The Diff-QuikTM rapid staining method was used to assess sperm morphology. Sperm cells were analyzed using a Zeiss optical Primo Star microscope (Carl Zeiss AG, Germany) after which the following defects were identified: decapitated-head, flattened-head, pin-head, bent neck and tail defects. Per sample, a total of 333 spermatozoa were counted (when possible) and for each spermatozoon only one defect was considered. Head-defects were considered more relevant than tail defects. The percentage of each defect was calculated.

\subsection{Morphometric analysis}

Prostate and testis tissues were fixed in $4 \%$ paraformaldehyde and embedded in paraffin to form paraffin-blocks. These paraffin blocks were sectioned $(5 \mu \mathrm{m})$ using a manual microtome. For each sample, two glass slides were collected with three or more cut sections per slide. One glass slide per sample was deparaffinized in xylol, rehydrated with alcohol in decreasing concentrations $(100 \%, 95 \%$ and $75 \%)$ and stained with haematoxylin and eosin (H\&E). Next, these specimens were examined using a bright-field optical microscope, and digital images were captured using ZEN Microscopy software. These images were further analyzed using ImageJ software. The mean area and number of seminiferous tubules in three random microscopic fields were measured. In addition, the thickness of arterial walls and the diameter of arterial lumina were measured and the ratios between them were calculated. Deparaffination and rehydration were also applied to the other glass slide using the same procedure, after which Sirius red staining was applied. The analysis of these glass slides was performed using the same procedure as described above. The basal lamina thickness was measured in three random microscopic fields.

\subsection{GeLC-MS/MS proteomics analysis}


Testes from each of six animals per experimental group were macerated in liquid nitrogen until a powder was obtained, lysed with the adequate volume of ice-cold $1 \mathrm{X}$ radioimmunoprecipitation assay (RIPA) lysis buffer ( $1 \mathrm{ml}$ buffer per $250 \mathrm{mg}$ of testis tissue) and incubated for $30 \mathrm{~min}$ at $4^{\circ} \mathrm{C}$ with agitation. Samples were centrifuged at $4^{\circ} \mathrm{C}$ for $20 \mathrm{~min}$ at $16000 \times \mathrm{g}$ after which the soluble fractions were collected. The protein concentrations of the soluble fractions were determined using a Pierce Bicinchoninic Acid (BCA) protein quantification assay kit (Fisher Scientific, Loures, Portugal).

Fifty $\mu \mathrm{g}$ protein from each sample was subjected to $12.5 \%$ sodium dodecyl sulfate (SDS)polyacrylamide gel electrophoresis (PAGE) according to Laemmly [26]. Gels were cut into pieces and extracted with a mixture $100 \mathrm{mM}$ NH4HCO3 in pure acetonitrile (ACN). Protein reduction was achieved through incubation in $10 \mathrm{mM}$ dithiothreitol $\left(60^{\circ} \mathrm{C}\right.$ in a heating block for $\left.30 \mathrm{~min}\right)$. Subsequently, proteins were alkylated in the dark with $55 \mathrm{mM}$ iodoacetamide (30 $\mathrm{min}$ at room temperature) and washed again. Digestion was performed overnight in the presence of trypsin $\left(37^{\circ} \mathrm{C}, 4 \mu \mathrm{g}\right.$ trypsin/sample). Peptide extraction was performed using $10 \%$ formic acid (FA), followed by a 1:1 mixture of ACN and ACN $90 \%$ and vacuum-dried. For sample clean-up, the peptide mixtures were resuspended in $2 \% \mathrm{ACN}$ and $1 \% \mathrm{FA}$ and purified using C18 OMIX tips Spin Columns (Agilent).

The peptide mixtures were re-suspended in $20 \mu 1$ loading solvent $(0.1 \%$ TFA in water/ACN, 2/98 $(\mathrm{v} / \mathrm{v})$ ). Next, $10 \mu \mathrm{l}$ of the peptide mixtures were analyzed using a LC-MS/MS system (Ultimate 3000 RSLC nano LC connected to a Q Exactive HF mass spectrometer (Thermo Fisher Scientific)). The peptides were loaded onto a trapping column (100 $\mu \mathrm{m}$ internal diameter (I.D. $) \times 20 \mathrm{~mm}, 5 \mu \mathrm{m}$ beads C18 Reprosil-HD) and subsequently separated on an analytical column (75 $\mu \mathrm{m}$ I.D. $\times 400 \mathrm{~mm}, 1.9 \mu \mathrm{m}$ beads C18 Reprosil-HD) using a non-linear 150 min gradient of 2-56\% solvent B, comprising $0.1 \%$ FA in water/ACN, 20/80 (v/v), at a flow rate of $250 \mathrm{nl} / \mathrm{min}$. Finally, a $10 \mathrm{~min}$ wash reaching $99 \%$ solvent B' was performed after which the columns were re-equilibrated with solvent A $\left(0.1 \% \mathrm{FA}\right.$ in water). Column temperatures were kept constant at $40^{\circ} \mathrm{C}$.

The mass spectrometer was operated in a data-dependent, positive ionization mode, automatically switching between MS and MS/MS acquisition for the 16 most abundant peaks in any given MS spectrum. The capillary temperature was $250^{\circ} \mathrm{C}$ and the source voltage was set to $2.8 \mathrm{kV}$. One MS1 scan (m/z 375-1500, AGC target 3E6 ions, maximum ion injection time of $60 \mathrm{~ms}$ ) acquired at a resolution of 60,000 (at $200 \mathrm{~m} / \mathrm{z}$ ) was followed by up to 16 tandem MS scans (resolution 15,000 at $200 \mathrm{~m} / \mathrm{z}$ ) of the most intense ions fulfilling the predefined selection criteria (AGC target 1E5 ions, maximum ion injection time of $80 \mathrm{~ms}$, isolation window of $1.5 \mathrm{~m} / \mathrm{z}$, fixed first mass of $145 \mathrm{~m} / \mathrm{z}$, spectrum data type: centroid, under fill ratio $1 \%$, intensity threshold $1.3 \mathrm{E} 4$, exclusion of unassigned, singly charged precursors, peptide match preferred, isotopes exclusion on, dynamic exclusion time of $12 \mathrm{~s}$ ). The HCD collision energy was set at $28 \%$ Normalized Collision Energy and the polydimethylcyclosiloxane background ion at 445.12002 Da was used for internal calibration (lock mass).

MaxQuant software was used with the Andromeda search engine. A false discovery rate (FDR) of $1 \%$ (for both the peptide and protein level) was considered. Spectra were searched against the Rattus norvegicus Swiss-Prot database (database release version of March 2018). The mass tolerance for precursor and fragment ions was set at 20 and $4.5 \mathrm{ppm}$, respectively, during the main search. Enzyme specificity was set at C-terminal to arginine and lysine, also allowing cleavage at arginine/lysine-proline bonds with a maximum of two missed 
cleavages. Variable modifications were set to oxidation of methionine (to sulfoxides), acetylation of protein $\mathrm{N}$ termini and phosphorylation of serine, threonine or tyrosine. A minimum of 2 peptides per group was considered for identification. Matching between runs using a 0.7 min match time window and a 20 min alignment time window was allowed. Proteins were quantified using the MaxLFQ algorithm, provided in the MaxQuant software.

To disclose the biological meaning of proteome data, bioinformatic tools were applied. Principal component analysis (PCA) and partial least squares discriminant analysis (PLS-DA) were applied to peak intensity data using SIMCA-P 11.5 (Umetrics, Umea, Sweden). For quantitative comparisons among groups, volcano plots were employed to annotate the proteins present at significantly distinct levels. Cytoscape (ClueGo+CluePedia plugins) was used to identify the biological processes more relevant in each of the conditions studied.

\subsection{Western blotting}

Thirty $\mu$ g protein from each sample ( 6 samples per group run in 3 gels) was resolved by $12 \%$ SDS-PAGE and proteins were electrotransferred onto nitrocellulose membranes. The gels were run at $200 \mathrm{~V}$ and then electrotransferred at $200 \mathrm{~mA}$ for $2 \mathrm{~h}$. The efficiency of the protein transference to the membranes was confirmed

using Ponceau Staining, which was also used as loading control. Non-specific protein-binding sites on the membranes were blocked with $5 \%$ bovine serum albumin (BSA) or $5 \%$ non-fat milk in $1 \times$ Tris-buffered saline (TBS $25 \mathrm{mM}$ Tris-HCl, pH 7.4, $150 \mathrm{mM} \mathrm{NaCl}$ ) containing $0.1 \%$ Tween 20 (TBS-T) for $1 \mathrm{~h}$. Next, the blots were washed with $1 \times \mathrm{TBS}-\mathrm{T}$ and incubated overnight or $1 \mathrm{~h}$ at $4^{\circ} \mathrm{C}$ with the respective primary antibodies: rabbit anti-AR (Sigma-Aldrich, 06-680), mouse anti-ER $\alpha$ (Santa Cruz Biotechnology, sc-8002), rabbit anti-VEGFA (abcam, ab46154), rabbit anti-Gpx4 (Sigma-Aldrich, ABC269) or mouse anti-TIM (Santa Cruz Biotechnology, sc166785). After incubation, the blots were washed $3 \times$ for $10 \mathrm{~min}$ with $1 \times$ TBS-T and then incubated with the appropriate secondary antibody for $1 \mathrm{~h}$ at RT. Next, the blots were washed three times for 10 min with $1 \times$ TBS$\mathrm{T}$ and once with $1 \times$ Tris-buffered saline (TBS $25 \mathrm{mM}$ Tris- $\mathrm{HCl}, \mathrm{pH} 7.4,150 \mathrm{mM} \mathrm{NaCl}$ ) (TBS) and immunodetected using an Odyssey infrared Imaging System (Li-COR® Biosciences, US). The results were analyzed using QuantityOne 4.6.6 (Basic)® software - Biorad.

\subsection{NMR metabolomics analysis}

Metabolites were extracted from liquid nitrogen-macerated testis samples using a modified version of the BlighDyer method [27]. Briefly, $500 \mu 180 \%$ cold methanol, $400 \mu 1$ cold chloroform and $200 \mu 1$ cold miliQ water were added to $50 \mathrm{mg}$ macerated tissue. The samples were kept on ice for $15 \mathrm{~min}$, centrifuged at $4^{\circ} \mathrm{C}$ for $10 \mathrm{~min}$ at $10000 \times \mathrm{g}$, and the aqueous phases were collected, dried in a speed vacuum concentrator and stored at $-80^{\circ} \mathrm{C}$.

At the time of NMR analysis, the aqueous extracts were reconstituted in $600 \mu 1$ PBS/D2O (100 mM, $\mathrm{pH}$ 7.4) containing $0.1 \mathrm{mM}$ trimethylsilylpropanoic acid (TSP-d4), after which $550 \mu \mathrm{l}$ was transferred into an NMR tube. ${ }^{1} \mathrm{H}-\mathrm{NMR}$ spectra were acquired on a Bruker Avance DRX-500 spectrometer operating at 500.13 $\mathrm{MHz}$ for ${ }^{1} \mathrm{H}$ observation, using a $5 \mathrm{~mm}$ Triple Resonance TXI probe at $298 \mathrm{~K}$. A 1D-NOESY pulse sequence with water presaturation ('noesypr1d' program in the Bruker library), 512 scans, a relaxation time of $2 \mathrm{~s}$ and an 
acquisition time of $2.3 \mathrm{~s}$ were employed. Spectral processing was performed using Topspin 4.0.6 and comprised manual phasing, baseline correction and signal calibration by the TSP signal (0 ppm).

PCA and PLS-DA were applied to total area-normalized and UV-scaled data using SIMCA-P 11.5 (Umetrics, Umea, Sweden). The results were represented as scores scatter plots and the cross-validated explained variance $\left(\mathrm{Q}^{2}\right)$ was used to assess the robustness of PLS-DA group discrimination. The PLS-DA loading plots were back-transformed by multiplying the loading weight by the standard deviation of each variable and colored according to variable importance to the projection (VIP) using the R-statistical software (R Foundation for Statistical Computing, Vienna Austria). Selected signals were integrated using Amix-Viewer and, for each metabolite, the percentage of variation, the respective error and the effect size (ES) were calculated. Metabolites presenting variations with an absolute ES $>0.8$ and with a percentage of variation $>5 \%$ (relative to controls) were represented in a heatmap colored as a function of percentage of variation, using the R-statistical software.

\subsection{Statistical analysis}

Univariate statistical analysis was performed using GraphPad Prism (version 7.0). The results were expressed as mean \pm standard error of the mean (SEM). The statistical significance of the differences between the four experimental groups were determined using the Kruskal-Wallis test followed by the multiple comparison posthoc Dunn's test. Statistical significance was assessed based on $p$-values, with values $<0.05$ being considered statistically significant.

\section{Results}

\subsection{Characterization of the animal model}

The histological analysis of prostate sections was performed according to the classic standards of classification, which is based on cell morphology (cellular and nuclear atypia, cell polarity, nuclear: cytoplasm ratio), cell crowding, number of mitotic features, atypical mitosis. This analysis confirmed that animals from the PCa groups exhibited prostate lesions, such as hyperplasia and microinvasive carcinoma. No obvious macroscopic lesions were observed. Fifty weeks of EX did not significantly affect the incidence of prostate lesions (Supplementary Table S1). The body weight, testis weight and testis mass-to-body weight ratio of the various experimental groups are described in Table 1. Sedentary PCa animals presented a reduction in body weight compared to sedentary controls, but this difference did not reach statistical significance. In exercised PCa animals, the reduction in body weight was more prominent ( $p<0.0001-\mathrm{PCa}+\mathrm{EX}$ vs. CONT+SED), reaching statistical significance when comparing PCa+EX and PCa+SED groups ( $p=0.0004-\mathrm{PCa}+\mathrm{EX}$ vs. PCa+SED). Compared to sedentary controls, sedentary $\mathrm{PCa}$ rats also exhibited a significant decrease in testis weight $(p=$ $0.0011-\mathrm{PCa}+\mathrm{SED}$ vs. CONT+SED), which was intensified in exercised animals $(p<0.00001-\mathrm{PCa}+\mathrm{EX}$ vs. $\mathrm{CONT}+\mathrm{SED})$. The testis mass-to-body weight ratio decreased in both sedentary and exercised PCa animals relative to controls ( $p=0.0002-\mathrm{PCa}+\mathrm{SED}$ vs. CONT $+\mathrm{SED} ; p=0.0009-\mathrm{PCa}+\mathrm{EX}$ vs. CONT+SED). 


\subsection{Evaluation of testicular function}

To determine the effect of PCa and EX on testis function, testosterone serum levels, androgen receptor (AR) and estrogen receptor $\alpha(E R \alpha)$ expression levels, sperm concentrations and morphologies, and testis histology were analyzed. Sedentary PCa rats exhibited significant higher testosterone serum levels, compared to sedentary controls $(p=0.0013-\mathrm{PCa}+\mathrm{SED}$ vs CONT+SED). This difference appeared to be intensified by EX $(p<0.0001$ - PCa+EX vs CONT+SED; Fig. 1a), although not reaching statistical significance when comparing PCa+EX and PCa+SED groups. The levels of AR and ER $\alpha$ in the testis tissues of the four experimental groups are presented in Fig. 1c and d. Neither PCa nor EX significantly affected AR and ER $\alpha$ testis expression.

The sperm concentrations were assessed in animals from the four experimental groups and data are presented in Fig. 1b. A marked and significant decrease in sperm concentration was observed in sedentary PCa rats, compared to the sedentary control group ( $p<0.0001-\mathrm{PCa}+\mathrm{SED}$ vs CONT+SED). In exercised PCa animals, the reduction in sperm concentration appeared to be slightly attenuated ( $P=0.0048-\mathrm{PCa}+\mathrm{EX}$ vs CONT+SED).

The sperm morphology was also compared between the different animal groups, based upon the percentage of different morphological features (Table 2). A decreased percentage of normal sperm forms was observed in sedentary PCa bearing animals, compared with the sedentary control group $(p<0.0001-\mathrm{PCa}+\mathrm{SED}$ vs CONT+SED). As observed for sperm concentration, in exercised PCa animals the decrease in normal sperm forms was slightly attenuated $(p<0.0001-\mathrm{PCa}+\mathrm{EX}$ vs CONT+SED). PCa also led to an increase in the percentage of decapitated-head (DH) $(p=0.0078-\mathrm{PCa}+\mathrm{SED}$ vs CONT+SED), flattened-head (FH) $(p=0.0009$ - PCa+SED vs CONT+SED; ) and pin-head (PH) ( $p=0.0006-\mathrm{PCa}+\mathrm{SED}$ vs CONT+SED) forms in sedentary animals. In exercised PCa animals the increase in DH forms appeared to be increased $(p<0.0001-\mathrm{PCa}+\mathrm{EX}$ vs CONT+SED) whereas the increase in FH ( $p=0.0171-\mathrm{PCa}+\mathrm{EX}$ vs CONT+SED) and PH forms seemed to be attenuated, reaching statistical significance only for PH forms when comparing PCa+EX and PCa+SED groups ( $p=0.0021-\mathrm{PCa}+\mathrm{EX}$ vs PCa+SED). Compared to sedentary controls, sedentary PCa rats appeared to exhibit decreased levels of bent-neck (BN) and tail defect (TD) sperm forms, which was more pronounced in exercised animals ( $p=0.0003-\mathrm{BN} ; p=0.0189-\mathrm{TD}-\mathrm{PCa}+\mathrm{EX}$ vs. CONT $+\mathrm{SED})$.

To determine the histological alterations in testicular tissues caused by $\mathrm{PCa}$ and EX, microscopic illustrations were captured and analyzed. Compared to sedentary controls, sedentary PCa animals exhibited higher numbers of seminiferous tubules per microscopic field with a reduced area $(p<0.0001-$ number and area of seminiferous tubules $-\mathrm{PCa}+\mathrm{SED}$ vs. CONT+SED; Fig. 2a, $\mathrm{b}$ and c). In exercised PCa animals, these PCa-induced alterations seemed to be attenuated $(p=0.0017$ - number and area of seminiferous tubules PCa+EX vs. CONT+SED; Fig. 2a, b and c), although statistical significance was not reached when PCa+EX and $\mathrm{PCa}+\mathrm{SED}$ groups were compared. PCa sedentary rats presented with a higher arterial thickness in the testis, which resulted in a reduced lumen diameter, or even in the closing of some arterial lumina, compared to the sedentary control group ( $p<0.0001-\mathrm{PCa}+\mathrm{SED}$ vs CONT+SED; Fig. $2 \mathrm{~d}$ ). PCa sedentary rats also exhibited a decreased cellular density with very few spermatids and virtually no mature spermatozoa in the centers of the seminiferous tubules, compared to sedentary control animals. Moreover, in the PCa sedentary group, some 
centers of the seminiferous tubules were filled with immature sperm cells, resembling primary or secondary spermatocytes, or presenting a laced aspect. Although the decrease in lumen diameter observed in sedentary PCa animals appeared to be attenuated in exercised PCa animals, no statistical significance was obtained when comparing $\mathrm{PCa}+\mathrm{EX}$ and $\mathrm{PCa}+\mathrm{SED}$ groups. In addition, an improvement in the maturation of sperm cells, with more spermatids and some sperm heads in the center of the seminiferous tubules, was observed in PCa+EX when compared to PCa+SED animals. Within control (non-PCa) rats, the exercised group also exhibited a slight increase in the arterial lumen diameter of testis tissue. However, as indicated by the observation of sperm cells at different maturation stages, including mature spermatozoa, exercise had no impact on sperm maturation in control animals.

To better understand some of the observed morphological alterations in testis tissues, the levels of vascular endothelial growth factor (VEGF), a marker of endothelial dysfunction, were measured. Sirius red staining of collagen fibers was also applied to testis sections to assess the contribution of fibrosis to testis adaptations. Decreased VEGF levels in the testis of sedentary PCa animals were observed when compared to the sedentary control group ( $p=0.0100-\mathrm{PCa}+\mathrm{SED}$ vs. CONT+SED). EX did not alter the PCa-induced decrease in VEGF levels ( $p=0.0132$ - PCa+EX vs. CONT+SED; Fig. 3a). Neither PCa nor EX altered the pattern of Sirius red staining of testis cross sections. Hence, none of these conditions was associated with testis collagen deposition (Fig. 3b). Quantitatively, the basal lamina thickness was similar between groups (Fig. 3c).

\subsection{Testis proteome analysis}

To further elucidate the molecular mechanisms underlying the observed PCa and EX-induced functional and morphological alterations, we set out to characterize the testis proteome. SDS-PAGE followed by LC-MS/MS analysis led to the identification of 616 distinct proteins (with more than 2 peptides, confidence level higher than $95 \%$, FDR lower than $1 \%$ and present in at least 3 animals from each experimental group) or 551 proteins (if only the proteins present in all animals from each group were considered; Supplementary Table S2). From the total proteins, 184 were common to all animals and found to be mostly involved in "metabolism" (according to STRING v10.5). Regarding these common proteins, Principal Component Analysis (PCA) revealed an evident separation between the 4 experimental groups, as seen in the PC1 vs. PC2 scores scatter plot (Supplementary Fig. S1a), indicating robust differences in the proteomic profiles induced by both PCa and EX, more evident in the PCa group. Subsequently, volcano plot analysis was used to further compare the relative protein abundances between groups (Supplementary Fig. S1b, c and d). A list of all the differentially expressed proteins, grouped according to the biological processes in which they are involved (according to STRING v10.5 and Uniprot database, considering FDR < 0.05) is presented in Table 3. Proteins from the biological processes "metabolic processes", "regulation of cell death" and "response to stress" were most affected by PCa. EX modulated proteins mainly involved "metabolic processes", "DNA repair" and "spermatogenesis/sperm function". Given that whole tissue samples were analyzed, the contribution of different cell types to these biological processes cannot be inferred.

To validate GeLC-MS/MS data, a number of protein targets was chosen based on their variation in response to PCa and/or EX (Table 3). Triosephosphate isomerase (Tpil) is a member of the glycolytic pathway, 
and glutathione peroxidase $4(G p x 4)$ is an essential antioxidant enzyme. Regarding Tpil, protein expression data revealed two different molecular masses - 26 and $31 \mathrm{KDa}$, which correspond, respectively, to a somatic cell isoform (sTpi1), previously detected in Sertoli and myoid cells, and a germ-cell specific isoform (gTpi1) [28,29]. Expression downregulation of gTpil was observed in PCa sedentary rats, compared with sedentary controls $(\mathrm{p}=0.0087-\mathrm{PCa}+\mathrm{SED}$ vs. CONT+SED). In exercised PCa animals, the PCa-induced decrease in gTpi1 levels was still present ( $\mathrm{p}=0.0115-\mathrm{PCa}+\mathrm{EX}$ vs. CONT+SED), although to a lesser extent. Still, no statistical significance was reached when comparing PCa+EX and PCa+SED groups (Fig. 4). The somatic cell isoform (sTpi1) did not change between groups (Fig. 4). Expression downregulation of Gpx4 was also noticed in the testes of sedentary PCa rats ( $p=0.0100-\mathrm{PCa}+\mathrm{SED}$ vs. CONT+SED). In exercised PCa animals, the testis expression of Gpx4 was also found to be decreased, although less prominently than in sedentary PCa animals. Again, the difference between the PCa+EX and PCa+SED groups was not statistically significant. These results are in agreement with the MS-based proteomic analysis.

\subsection{Testis metabolome analysis}

Since most of the differentially expressed proteins were associated with metabolic processes, a metabolomic analysis was next performed. Principal Component Analysis (PCA) of 1H NMR spectral profiles corresponding to the four experimental groups revealed an evident separation between the non-PCa and PCa samples (Supplementary Fig. S2a). Conversely, the separation between exercised and sedentary groups was less clear. Subsequent pairwise comparisons showed robust discrimination between the different groups, apparent in both PCA and PLS-DA score plots and explained by the respective LV1 loadings (Supplementary Fig. S2b, c and d). After quantification through spectral integration of signals representing individual metabolites, the variations with a higher magnitude ( $|\mathrm{ES}|>0.8$, according to Berben, 2012 [30]) were summarized in the form of a heatmap (Fig. 5). We found that prostate tumor development had an extensive impact on the testicular metabolic composition, as shown by the 1 st column of the heatmap (PCa+SED vs. CONT+SED). Relevant increases were noted for myo-inositol, glucose, some amino acids (tyrosine, aspartate and branched chain amino acids), (phospho)ethanolamine, uridine, acetate, taurine and ascorbate. In contrast, compared to control tissues, PCa testes showed decreased levels of $\beta$-hydroxybutyrate, betaine, glycerophosphocholine, glutathione (GSH), succinate, UDP-glucose, alanine, glutamate, adenosine and creatine. Notably, in exercised PCa animals (2nd column of the heatmap; PCa+EX vs. CONT+SED), some of these alterations were attenuated (namely the decreases in $\beta$-hydroxybutyrate and creatine, and the increases in taurine, acetate, (phospho)ethanolamine, tyrosine and m-inositol) or even prevented. In particular, in PCa animals, EX prevented the increases in ascorbate, uridine and glucose, as well as the decrease in succinate. Most changes induced by EX in PCa animals were not observed in healthy animals ( $3^{\text {rd }}$ column of the heatmap; CONT+EX vs. CONT+SED).

\section{Discussion}


Prostate cancer $(\mathrm{PCa})$ is one of the most common and fatal types of cancer in men. The treatment and prevention of this disease remains a major challenge [31]. Exercise training (EX) has been associated with numerous health-related benefits and is often regarded as a polypill against disease [32]. Indeed, it has become clear that EX plays a vital role in the treatment and prevention of several pathologies, including cancer [32-34]. To provide molecular insight into the crosstalk between PCa and EX, the present work focused on the remodeling of testis, one of the organs most affected by PCa. To the best of our knowledge, as yet only a single case-control study has focused on the effect of lifelong EX in PCa [35] and none have evaluated its effect on testicular tissue. Here, an animal model (Wistar Unilever rat) was chosen based on its ability to produce adenocarcinomas that originate from a prostate lobe for which there is a human homologue. A combination of hormonal stimulation - testosterone - with a carcinogen - MNU - was used to induce PCa's which are associated with a high rate of accessory sex gland tumor development [36,37]. As expected, anatomopathological analyses of prostate sections confirmed the presence of adenocarcinoma in PCa rats (Supplementary Table S1), supporting the suitability of this pre-clinical model to test preventive and therapeutic options for the management of this type of cancer [38]. The analysis of circulating testosterone revealed significantly increased levels (12 to 15-fold) in PCa rats, which appeared to be a consequence of the PCa-induction protocol. Thus, it could be that the changes observed in the testis of PCa rats may result from not only prostate lesions but also from testosterone regulation. Thus, one may hypothesize that the systemic adaptations promoted by PCa, and even by EX, might be attenuated by the high circulating levels of testosterone. Indeed, PCa is usually diagnosed in aged males, when testosterone levels go down [39]. However, the identical expression of AR and ER $\alpha$ in the testis of the different groups suggests that neither testosterone nor its major product, estradiol, contributed significantly to the changes observed in the PCa rat testes, indicating that prostate lesions were the major contributors to the observed testicular adaptations.

Decreased sperm counts and an altered morphologies were noted in the testis of PCa animals, similar to those described by Toni et al. [4]. Spermatogenesis was disrupted near the meiotic stage in PCa rats, with virtually no elongating spermatids and mature spermatozoa. Spermatogenesis is a tightly regulated process associated with high grades of cell proliferation and differentiation, rendering the testis highly vulnerable to oxidative stress [40,41]. Reduced testis blood flow, as a result of smooth muscle cell hyperproliferation, may be associated with oxidative stress [42]. Indeed, decreased testis antioxidant defenses, like Gpx4, GSH, betaine and creatine were noted in PCa animals. On the other hand, the slight increase in testicular ascorbate levels could be a compensatory mechanism for the observed loss of antioxidant capacity. These data suggest that PCainduced oxidative stress may have contributed to spermatogenesis impairment via germ cell apoptosis, corroborated by changes in the expression of cell death-related proteins (Table 3) [43,44].

EX has been associated with alterations in reproductive hormonal profiles and in sperm quality parameters. However, the magnitude and direction of these alterations is controversial, which may at least partially be explained by the distinct types, durations and intensities of the exercise programs applied in different studies [20,45-48]. In the present work, although EX did not significantly prevent PCa-induced impairment of sperm quality parameters, an apparent attenuation of $\mathrm{PCa}$-induced germ cell maturation arrest was noted in exercised PCa animals. Corroborating these findings, we found that EX prevented the PCa-induced 
downregulation of phosphoprotein phosphatase 1c (Ppplcc) and attenuated the downregulation of large prolinerich protein (Bag6), both of which are involved in spermatogenesis and required for normal sperm generation [49,50] (Table 3). Phosphatidylethanolamine-binding protein 1 (Pebp1) and protein disulfide-isomerase like (Pdilt) are expressed exclusively in post-meiotic germ cells and its $\mathrm{PCa}$-induced downregulation was also found to be attenuated by EX, confirming an improvement of germ cell maturation [51,52]. EX did not prevent PCainduced oxidative stress, but modulated DNA repair mechanisms, since all proteins involved in this process were upregulated (Table 3). In accordance to the activation of DNA repair mechanisms, EX also attenuated the PCa-induced upregulation of clusterin $(\mathrm{Clu})$, a protein that has been found to be associated with sperm DNA damage and to modulate DNA damage-induced cell death [53,54]. DNA repair mechanisms ensure genomic integrity and germ cell stability, preventing apoptosis and thus enhancing germ cell development [55].

The analysis of the testis proteome revealed that a comparatively large number of proteins involved in metabolism were modulated by both PCa and EX. Testis metabolism depends on the cell type considered: Sertoli cells exhibit a high metabolic flexibility and are able to metabolize not only glucose, but also fatty acids, ketone bodies, glycogen and branched chain amino acids. Germ cells, however, depend almost exclusively on lactate and glucose for their energy production. Increased levels of glucose in the testis of sedentary PCa animals suggests a reduction in glucose utilization which, based also on the decreased levels of Tpil in germ cells of PCa animals, may reflect a general impairment of glycolysis. Concordantly, deregulation of glycolytic enzymes, including Tpi1, has been associated by others with impaired spermatogenesis and germ cell apoptosis [56]. In an attempt to compensate for decreased glucose metabolism, Sertoli cells appeared to increase the metabolization of ketone bodies, particularly $\beta$-hydroxybutyrate, as an alternative energy source, leading to decreased testis levels. Such variation may also have repercussions in Leydig cells. These cells utilize $\beta$ hydroxybutyrate, in addition to glucose, to maintain steroidogenesis, suggesting an impairment of this process, that may be compensated by the higher glucose levels in the testis [57]. An accumulation of branched-chain amino acids (valine, leucine and isoleucine) was also noted in the testes of PCa animals. Increased testis levels of branched-chain amino acids has previously been associated with an age-related decline in testicular function, suggesting that it may have contributed to the observed PCa impaired spermatogenesis [58]. Lastly, decreased levels of UDP-glucose suggest an increased metabolization of glycogen in Sertoli cells, confirming the suggestion that Sertoli cells may increase the use of alternative metabolic substrates.

We found that EX prevented or attenuated some of the effects of PCa on testis metabolism. In particular, it prevented the PCa-induced testis accumulation of glucose, suggesting a recovery of the glycolytic pathway, which is underscored by the less prominent decrease of Tpil levels in the testes of exercised PCa animals. Also, in agreement with this hypothesis, EX attenuated the decrease in the levels of $\beta$-hydroxybutyrate. Such attenuation could be related to higher levels of testosterone observed in exercised PCa animals, as expected from previous studies [59], since Leydig cells may employ $\beta$-hydroxybutyrate as a substrate for energy production to maintain steroidogenesis.

In summary, our data confirm that PCa negatively affects testicular function, possibly through oxidative stress-induced DNA damage arising from decreased testis blood flow, which in turn may contribute to germ cell apoptosis and consequent impairment of spermatogenesis. An altered metabolism characterized by 
glycolysis downregulation, increased ketone bodies and glycogen metabolization, together with accumulation of branched chain amino acids, seems to energetically support testis function in PCa animals. Fifty weeks of moderate intensity treadmill EX prevented $\mathrm{PCa}$-induced testis remodeling to some extent, mainly through the activation of DNA repair mechanisms, along with a recovery of the glycolytic pathway and the attenuation of PCa-induced increases in ketone body metabolization. Figure 6 summarizes our model regarding the molecular alterations underlying testis metabolic remodeling induced by PCa and EX, emphasizing the role of Sertoli and germ cells in these adaptations.

\section{Acknowledgments}

We are thankful to the Portuguese Foundation for Science and Technology (FCT), the European Union, QREN, FEDER and COMPETE for funding the Institute of Biomedicine - iBiMED (UID/BIM/04501/2013, POCI-010145-FEDER-007628 and UID/BIM/04501/2019), Organic Chemistry, Natural and Agro-food Products QOPNA (UID/QUI/00062/2013), Aveiro Institute of Materials - CICECO (UID/CTM/50011/2019), Center for the Research and Technology of Agro-Environmental and Biological Sciences - CITAB (UID/AGR/04033/2019) and Research Centre in Physical Activity, Health and Leisure - CIAFEL (UID/DTP/00617/2019) research units, and the research project RUNawayPCa (POCI-01-0145-FEDER006958 and PTDC/DTP-DES/6077/2014). We also acknowledge the Portuguese National NMR (PTNMR) Network, supported by FCT funds, and the European Union Framework Programme for Research and Innovation HORIZON 2020, under the TEAMING Grant agreement No 739572 - The Discoveries CTR. We are also thankful to Celeste Resende for assistance in sample preparations for histological analyses.

\section{Compliance with ethical standards}

Ethical approval: The animal protocol was approved by the animal well-being responsible organ of UTAD and by Direção Geral de Alimentação e Veterinária-DGAV (license nº 021326).

Conflicts of Interest: The authors declare that they have no conflict of interest

\section{Author Contribution Statement}

BM - study execution, data analysis and discussion, and original draft manuscript preparation; DP -serum and testis biochemical analyses; MCH - serum and testis biochemical analyses and semen analyses; MJF -semen analyses; FS - prostate histological analyses, RV - proteomics data analyses; JAD - testis histological analyses, IFD - metabolomics data analyses and study discussion, JH - data discussion and English editing, $\mathrm{PO}$ - animal protocol implementation and data discussion, $\mathrm{RF}$ and MF - study design and data discussion. All authors revised the manuscript and approved the final version. 


\section{References}

1. F. Bray, J. Ferlay, I. Soerjomataram, R. L. Siegel, L. A. Torre, and A. Jemal, Global cancer statistics 2018: GLOBOCAN estimates of incidence and mortality worldwide for 36 cancers in 185 countries. CA. Cancer J. Clin. 68, 394-424 (2018)

2. P. L. Zhang, S. Rosen, R. Veeramachaneni, J. Kao, W. C. DeWolf, and G. Bubley, Association between prostate cancer and serum testosterone levels., Prostate 53, 179-82 (2002)

3. T. Imamoto, H. Suzuki, M. Yano, K. Kawamura, N. Kamiya, K. Araki, A. Komiya, Y. Naya, T. Shiraishi, and T. Ichikawa, Does presence of prostate cancer affect serum testosterone levels in clinically localized prostate cancer patients?, Prostate Cancer Prostatic Dis. 12, 78-82 (2009)

4. L. De Toni, A. Di Nisio, E. Speltra, M. S. Rocca, M. Ghezzi, D. Zuccarello, N. Turiaco, A. Ferlin, and C. Foresta, Polymorphism rs2274911 of GPRC6A as a Novel Risk Factor for Testis Failure, J. Clin. Endocrinol. Metab. 101, 953-961 (2016)

5. A. M. Traish, F. Saad, and A. Guay, The dark side of testosterone deficiency: II. type 2 diabetes and insulin resistance, J. Androl. 30, 23-32 (2009)

6. G. Corona, G. Rastrelli, M. Monami, A. Guay, J. Buvat, A. Sforza, G. Forti, E. Mannucci, and M. Maggi, Hypogonadism as a risk factor for cardiovascular mortality in men: A meta-analytic study, Eur. J. Endocrinol. 165, 687-701 (2011)

7. E. L. Richman, S. A. Kenfield, M. J. Stampfer, A. Paciorek, P. R. Carroll, and J. M. Chan, Physical Activity after Diagnosis and Risk of Prostate Cancer Progression: Data from the Cancer of the Prostate Strategic Urologic Research Endeavor, Cancer Res. 71, 3889-3895 (2011)

8. S. A. Kenfield, M. J. Stampfer, E. Giovannucci, and J. M. Chan, Physical Activity and Survival After Prostate Cancer Diagnosis in the Health Professionals Follow-Up Study, J. Clin. Oncol. 29, 726-732 (2011) 9. S. E. Bonn, A. Sjolander, Y. T. Lagerros, F. Wiklund, P. Stattin, E. Holmberg, H. Gronberg, and K. Balter, Physical Activity and Survival among Men Diagnosed with Prostate Cancer, Cancer Epidemiol. Biomarkers Prev. 24, 57-64 (2015)

10. C. M. Friedenreich, Q. Wang, H. K. Neilson, K. A. Kopciuk, S. E. McGregor, and K. S. Courneya, Physical Activity and Survival After Prostate Cancer, Eur. Urol. 70, 576-585 (2016)

11. Y. Wang, E. J. Jacobs, S. M. Gapstur, M. L. Maliniak, T. Gansler, M. L. McCullough, V. L. Stevens, and A. V. Patel, Recreational Physical Activity in Relation to Prostate Cancer-specific Mortality Among Men with Nonmetastatic Prostate Cancer, Eur. Urol. 72, 931-939 (2017)

12. A. A. Singh, L. W. Jones, J. A. Antonelli, L. Gerber, E. E. Calloway, K. H. Shuler, S. J. Freedland, D. J.

Grant, C. Hoyo, and L. L. Bañez, Association between exercise and primary incidence of prostate cancer:

Does race matter?, Cancer 119, 1338-1343 (2013)

13. C. De Nunzio, F. Presicce, R. Lombardo, F. Cancrini, S. Petta, A. Trucchi, M. Gacci, L. Cindolo, and A. Tubaro, Physical activity as a risk factor for prostate cancer diagnosis: A prospective biopsy cohort analysis, BJU Int. 117, E29-E35 (2016)

14. E. Giovannucci, Y. Liu, L. MF, S. MJ, W. WC, E. L. Giovannucci, Y. Liu, M. F. Leitzmann, M. J. 
Stampfer, and W. C. Willett, A prospective study of physical activity and incident and fatal prostate cancer., Arch. Intern. Med. 165, 1005-1010 (2005)

15. A. V Patel, C. Rodriguez, E. J. Jacobs, L. Solomon, M. J. Thun, and E. E. Calle, Recreational physical activity and risk of prostate cancer in a large cohort of U.S. men, Cancer Epidemiol Biomarkers Prev 14, 275279 (2005)

16. R. J. Barnard, T. H. Ngo, P. S. Leung, W. J. Aronson, and L. A. Golding, A low-fat diet and/or strenuous exercise alters the IGF axis in vivo and reduces prostate tumor cell growth in vitro, Prostate 56, 201-206 (2003)

17. G. R. Teixeira, W. J. Fávaro, P. F. F. Pinheiro, L. G. a Chuffa, J. P. a Amorim, L. O. Mendes, B. a Fioruci, E. Oba, O. a Martins, M. Martinez, and F. E. Martinez, Physical exercise on the rat ventral prostate: steroid hormone receptors, apoptosis and cell proliferation., Scand. J. Med. Sci. Sports 22, e86-92 (2012) 18. M. Veljkovic, V. Dopsaj, M. Dopsaj, D. R. Branch, N. Veljkovic, M. M. Sakarellos-Daitsiotis, V. Veljkovic, S. Glisic, and A. Colombatti, Physical activity and natural Anti-VIP antibodies: Potential role in breast and prostate cancer therapy, PLoS One 6, 2-7 (2011)

19. I. Manna, K. Jana, and P. K. Samanta, Effect of intensive exercise-induced testicular gametogenic and steroidogenic disorders in mature male Wistar strain rats: A correlative approach to oxidative stress, Acta Physiol. Scand. 178, 33-40 (2003)

20. M. R. Safarinejad, K. Azma, and A. A. Kolahi, The Effects of intensive, long-term treadmill running on reproductive hormones, hypothalamus-pituitary-testis axis, and semen quality: A randomized controlled study, J. Endocrinol. 200, 259-271 (2009)

21. K. Jana, P. K. Samanta, I. Manna, P. Ghosh, N. Singh, R. P. Khetan, and B. R. Ray, Protective effect of sodium selenite and zinc sulfate on intensive swimming-induced testicular gamatogenic and steroidogenic disorders in mature male rats., Appl. Physiol. Nutr. Metab. 33, 903-14 (2008)

22. Y. Guo and E. Li, Proteomics analysis of intensive exercise-induced disorders of gametogenesis in the testis using isobaric tags for relative and absolute quantification (iTRAQ) analysis, Reprod. Fertil. Dev. 30, 1785-1793 (2018)

23. X. Zhao, Y. Bian, Y. Sun, L. Li, L. Wang, C. Zhao, Y. Shen, Q. Song, Y. Qu, S. Niu, W. Wu, and F. Gao, Effects of moderate exercise over different phases on age-related physiological dysfunction in testes of SAMP8 mice, Exp. Gerontol. 48, 869-880 (2013)

24. X. Yi, H. Gao, D. Chen, D. Tang, W. Huang, T. Li, T. Ma, and B. Chang, Effects of obesity and exercise on testicular leptin signal transduction and testosterone biosynthesis in male mice, Am. J. Physiol. - Regul. Integr. Comp. Physiol. 312, R501-R510 (2017)

25. J. Magalhães, A. Ascensão, A. I. Padrão, I. M. Aleixo, E. Santos-Alves, S. Rocha-Rodrigues, A. Ferreira, L. Korrodi-Gregório, R. Vitorino, R. Ferreira, and M. Fardilha, Can exercise training counteract doxorubicininduced oxidative damage of testis proteome?, Toxicol. Lett. 280, 57-69 (2017)

26. U. K. Laemmli, Cleavage of structural proteins during the assembly of the head of bacteriophage T4, Nature 227, 680-685 (1970)

27. E. G. Blich and W. J. Dyer, Canadian Journal of Biochemistry and Physiology, Can. J. Biochem. Physiol. 
37, 911-917 (1959)

28. D. L. Russell and K. H. Kim, Expression of triosephosphate isomerase transcripts in rat testis: evidence for retinol regulation and a novel germ cell transcript., Biol. Reprod. 55, 11-18 (1996)

29. T. W. Ijiri, M. L. Vadnais, A. M. Lin, A. P. Huang, W. Cao, T. Merdiushev, and G. L. Gerton, Male mice express spermatogenic cell-specific triosephosphate isomerase isozymes, Mol. Reprod. Dev. 80, 862-870 (2013)

30. L. Berben, S. M. Sereika, and S. Engberg, Effect size estimation: Methods and examples, Int. J. Nurs. Stud. 49, 1039-1047 (2012)

31. J. Ferlay, I. Soerjomataram, R. Dikshit, S. Eser, C. Mathers, M. Rebelo, D. M. Parkin, D. Forman, and F. Bray, Cancer incidence and mortality worldwide: Sources, methods and major patterns in GLOBOCAN 2012, Int. J. Cancer 136, E359-E386 (2015)

32. C. Fiuza-Luces, N. Garatachea, N. A. Berger, and A. Lucia, Exercise is the Real Polypill, Physiology 28, 330-358 (2013)

33. K. S. Courneya and C. M. Friedenreich, Framework PEACE: An organizational model for examining physical exercise across the cancer experience, Ann. Behav. Med. 23, 263-272 (2001)

34. J. A. Hawley, M. Hargreaves, M. J. Joyner, and J. R. Zierath, Integrative biology of exercise, Cell 159, 738-749 (2014)

35. C. M. Friedenreich, S. E. McGregor, K. S. Courneya, S. J. Angyalfi, and F. G. Elliott, Case-control study of lifetime total physical activity and prostate cancer risk, Am. J. Epidemiol. 159, 740-749 (2004)

36. D. L. Mccormick, K. V. N. Rao, L. Dooley, V. E. Steele, R. A. Lubet, G. J. Kelloff, and M. C. Bosland, Influence of N -Methyl- N -Nitrosourea, Testosterone, and N - ( 4-Hydroxyphenyl ) -all- trans -retinamide on Prostate Cancer Induction in Wistar-Unilever Rats $\hat{A}_{i}$ ra / is-retinamide on Prostate Cancer Induction in Wistar-Unilever Rats1, Cancer Res. 3282-3288 (1998)

37. M. C. Bosland, Testosterone treatment is a potent tumor promoter for the rat prostate, Endocrinology $\mathbf{1 5 5}$, 4629-4633 (2014)

38. E. Nascimento-Gonçalves, A. I. Faustino-Rocha, F. Seixas, M. Ginja, B. Colaço, R. Ferreira, M. Fardilha, and P. A. Oliveira, Modelling human prostate cancer: Rat models, Life Sci. 203, 210-224 (2018)

39. J. D. Tobin, E. J. Metter, J. Pearson, M. R. Blackman, and S. M. Harman, Longitudinal Effects of Aging on Serum Total and Free Testosterone Levels in Healthy Men, J. Clin. Endocrinol. Metab. 86, 724-731 (2014)

40. J. G. Reyes, J. G. Farias, S. Henríquez-Olavarrieta, E. Madrid, M. Parraga, A. B. Zepeda, and R. D. Moreno, The hypoxic testicle: Physiology and pathophysiology, Oxid. Med. Cell. Longev. 2012, (2012) 41. N. Asadi, M. Bahmani, A. Kheradmand, and M. Rafieian-Kopaei, The impact of oxidative stress on testicular function and the role of antioxidants in improving it: A review, J. Clin. Diagnostic Res. 11, IE01IE05 (2017)

42. S. B. Guimarães, P. H. U. Barbosa, J. M. V. Santos, P. R. L. de Vasconcelos, A. A. Aragão, and O. de S. Kimura, Oxidative stress induced by torsion of the spermatic cord in young rats, Acta Cir. Bras. 22, 30-33 (2007) 
43. W. P. Roos and B. Kaina, DNA damage-induced cell death by apoptosis, Trends Mol. Med. 12, 440-450 (2006)

44. B. Kaina, DNA damage-triggered apoptosis: Critical role of DNA repair, double-strand breaks, cell proliferation and signaling, Biochem. Pharmacol. 66, 1547-1554 (2003)

45. M. Grandys, J. Majerczak, K. Duda, J. Zapart-Bukowska, J. Kulpa, and J. A. Zoladz, Endurance training of moderate intensity increases testosterone concentration in young, healthy men, Int. J. Sports Med. 30, 489495 (2009)

46. L. Priskorn, T. K. Jensen, A. K. Bang, L. Nordkap, U. N. Joensen, T. H. Lassen, I. A. Olesen, S. H. Swan, N. E. Skakkebaek, and N. Jørgensen, Is Sedentary Lifestyle Associated with Testicular Function? A CrossSectional Study of 1,210 Men, Am. J. Epidemiol. 184, 284-294 (2016)

47. D. Vaamonde, M. E. Da Silva-Grigoletto, J. M. García-Manso, N. Barrera, and R. Vaamonde-Lemos, Physically active men show better semen parameters and hormone values than sedentary men, Eur. J. Appl. Physiol. 112, 3267-3273 (2012)

48. A. J. Gaskins, J. Mendiola, M. Afeiche, N. Jørgensen, S. H. Swan, and J. E. Chavarro, Physical activity and television watching in relation to semen quality in young men, Br. J. Sports Med. 49, 265-270 (2015) 49. N. Sinha, P. Puri, A. C. Nairn, and S. Vijayaraghavan, Selective Ablation of Ppp1cc Gene in Testicular Germ Cells Causes Oligo-Teratozoospermia and Infertility in Mice1, Biol. Reprod. 89, 1-15 (2013)

50. T. Sasaki, E. Marcon, T. McQuire, Y. Arai, P. B. Moens, and H. Okada, Bat3 deficiency accelerates the degradation of Hsp70-2/HspA2 during spermatogenesis, J. Cell Biol. 182, 449-458 (2008)

51. W. Xu, P. Fang, Z. Zhu, J. Dai, D. Nie, Z. Chen, Q. Qin, L. Wang, Z. Wang, and Z. Qiao, Cigarette Smoking Exposure Alters Pebp1 DNA Methylation and Protein Profile Involved in MAPK Signaling Pathway in Mice Testis 1, 89, 1-11 (2013)

52. M. van Lith, A.-R. Karala, D. Bown, J. A. Gatehouse, L. W. Ruddock, P. T. K. Saunders, and A. M.

Benham, A Developmentally Regulated Chaperone Complex for the Endoplasmic Reticulum of Male Haploid Germ Cells, Mol. Biol. Cell 18, 2795-2804 (2007)

53. X. Ming, C. Bao, T. Hong, Y. Yang, X. Chen, Y.-S. Jung, and Y. Qian, Clusterin, a Novel DEC1 Target, Modulates DNA Damage-Mediated Cell Death, Mol. Cancer Res. 16, 1641-1651 (2018)

54. B. Muciaccia, S. Pensini, F. Culasso, F. Padula, D. Paoli, L. Gandini, C. Di Veroli, G. Bianchini, M. Stefanini, and A. D'Agostino, Higher clusterin immunolabeling and sperm DNA damage levels in hypertensive men compared with controls, Hum. Reprod. 27, 2267-2276 (2012)

55. S. Gunes, M. Al-Sadaan, and A. Agarwal, Spermatogenesis, DNA damage and DNA repair mechanisms in male infertility, Reprod. Biomed. Online 31, 309-319 (2015)

56. E. Li, Y. Guo, Q. Ning, S. Zhang, and D. Li, Research for the effect of octylphenol on spermatogenesis and proteomic analysis in octylphenol-treated mice testes, Cell Biol. Int. 35, 305-309 (2011)

57. P. Amrolia, B. A. Cooke, M. H. Sullivan, D. Garside, and S. A. Baldwin, An investigation of glucose uptake in relation to steroidogenesis in rat testis and tumour Leydig cells, Biochem. J. 249, 925-928 (1988) 58. I. Jarak, S. Almeida, R. A. Carvalho, M. Sousa, A. Barros, M. G. Alves, and P. F. Oliveira, Senescence and declining reproductive potential: Insight into molecular mechanisms through testicular metabolomics, 
Biochim. Biophys. Acta - Mol. Basis Dis. 1864, 3388-3396 (2018)

59. D. Y. Seo, S. R. Lee, H. B. Kwak, H. Park, K. W. Seo, Y. H. Noh, K. M. Song, J. K. Ryu, K. S. Ko, B. D. Rhee, and J. Han, Exercise training causes a partial improvement through increasing testosterone and eNOS for erectile function in middle-aged rats, Exp. Gerontol. 108, 131-138 (2018) 


\section{Figures captions:}

Figure 1 Influence of prostate cancer (PCa) and exercise training (EX) on (a) testosterone serum levels (pg/ml) and (b) sperm concentration, and on (c) AR and (d) ER $\alpha$ testis levels (a representative Western blot of 3 experiments is shown above the graphs). The results are expressed as mean \pm SEM and statistical significance is presented based on $p$-value: ${ }^{* *} p<0.01,{ }^{* * * *} p<<0.0001$

Figure 2 Influence of prostate cancer (PCa) and exercise training (EX) on (a) histological morphology of rat testes (hematoxylin and eosin, 10× and 40x amplification), (b) number of seminiferous tubules per microscopic field, (c) area of seminiferous tubules and (d) ratio between the arterial lumen diameter and the arterial thickness. The quantitative results are expressed as mean \pm SEM and statistical significance is presented based on $p$-value. $* * p<<0.01 ; * * * * p<0.0001$

Figure 3 Influence of prostate cancer (PCa) and exercise training (EX) on (a) VEGF testis levels (a representative Western blot of 3 experiments is shown above the graph), (b) testis basal lamina thickness ( $\mu \mathrm{m})$ and (c) histological morphology of rat testes (Sirius red, $40 \times$ and $100 \times$ amplification). The quantitative results are expressed as mean \pm SEM and statistical significance is presented based on $p$-value. ${ }^{*} p<0.05$

Figure 4 Influence of prostate cancer (PCa) and exercise training (EX) on Tpil and Gpx4 testis levels. The results are expressed as mean \pm SEM and statistical significance is presented based on $p$-value: $* p<0.05 ; * * p$ $<0.01$. A representative Western blot of 3 experiments is shown above the graph

Figure 5 Heatmap of the main metabolite variations between CONT+EX compared with CONT+SED $\left(1^{\text {st }}\right.$ column), PCa+SED compared with CONT + SED $\left(2^{\text {nd }}\right.$ column $)$ and PCa+EX compared with CONT+SED ( $3^{\text {rd }}$ column). The results are expressed according to percentage of variation (color scale). Variations with percentage of variation $<5 \%$ and with an $\mid$ effect size $\mid<0.8$ were excluded. Statistically significant variations are presented based on $p$-value. ${ }^{*} p<0.05 ;{ }^{* *} p<<0.01$

Figure 6 Overview of the main alterations identified in testis from animals with prostate lesions (orange $\mathrm{PCa}+\mathrm{SED}$ vs. CONT+SED) and those subjected to 50 weeks of exercise training (green - PCa+EX vs. CONT+SED). The contributions of Sertoli and germ cells are highlighted, since these cells seem to be responsible for the alterations observed

GLUT: glucose transporter; GP: glycogen phosphorylase; ALT: alanine aminotransferase; LDHC: lactate dehydrogenase C; PDH: pyruvate dehydrogenase; IDH3A: isocitrate dehydrogenase [NAD] subunit alpha, mitochondrial; BCAT: branched chain aminotransferase; MCT4: monocarboxylate transporter 4; MCT2: monocarboxylate transporter 2; TPi1: triosephosphate isomerase 1 


\section{Supplementary material:}

Supplementary Table S1: The influence of prostate cancer (PCa) and exercise training (EX) on the incidence of non neoplastic and pre-neoplastic and neoplastic prostate lesions

Supplementary Table S2 Data from MS/MS analysis extracted from the MaxQuant software, including the identified proteins and the label-free quantification (LFQ) of each sample

Supplementary Figure S1 (a) PCA scores plots of proteomics data, comparing the four experimental groups and differential abundance analysis for (b) CONT+EX vs CONT+SED; (c) PCa+SED vs CONT+SED; and (d) PCa+EX vs CONT+SED

Supplementary Figure S2 (a) PCA scores plot of the metabolomics data comparing the four experimental groups; and PCA and PLS-DA scores plots and respective PLS-DA LV1 loadings plots of ${ }^{1} \mathrm{H}$ NMR spectra for (b) CONT+EX; (c) $\mathrm{PCa}+\mathrm{SED}$; (d) PCa+EX, when compared with CONT+SED. Loadings plots are colored as a function of variable importance in projection (VIP) and the assignment of the main signals is indicated 


\section{Tables}

Table 1 The influence of prostate cancer (PCa) and exercise training (EX) on animals' body weight, testis weight and testis-to-body weight ratio. The results were expressed as mean \pm SEM and the statistical

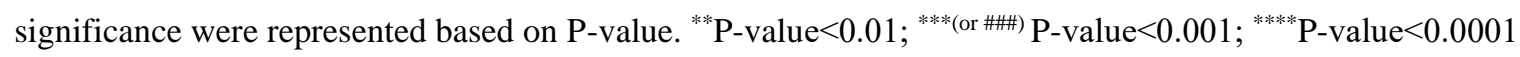

\begin{tabular}{|ccccc|}
\hline $\begin{array}{c}\text { Mean } \\
\text { Weight }\end{array}$ & CONT+SED & CONT+EX & PCa+SED & PCa+EX \\
\hline Body (g) & $541.05 \pm 13.42$ & $434.81 \pm 8.91^{* *}$ & $494.59 \pm 9.12$ & $421.64 \pm 7.40^{* * * *}$ \#\#\# \\
\hline Testis (g) & $1.591 \pm 0.031$ & $1.133 \pm 0.142$ & $0.657 \pm 0.069^{* *}$ & $0.553 \pm 0.011^{* * * *}$ \\
\hline $\begin{array}{c}\text { Testis/ } \\
\text { Body weight } \\
\text { (mg/g) }\end{array}$ & $2.831 \pm 0.075$ & $2.601 \pm 0.033$ & $1.316 \pm 0.117^{* * *}$ & $1.320 \pm 0.039^{* * *}$ \\
\hline & vs. CONT+SED & vs. CONT+SED & $\begin{array}{c}* \text { vs. CONT+SED } \\
\text { \# vs. PCa+SED }\end{array}$ \\
\hline
\end{tabular}


Table 2 The influence of prostate cancer (PCa) and exercise training (EX) on percentage of sperm morphologic forms. The results were expressed as mean \pm SEM and the statistical significance were represented based on $P$ value. ${ }^{*} P$-value $<0.05 ;{ }^{* *(\text { or } \#)} P$-value $<0.01 ;{ }^{* * *} P$-value $<0.001 ;{ }^{* * * *} P$-value $<0.0001$

N: normal; DH: decapitated-head; FH: flattened-head; PH: pin-head; BN: bent-neck; TD: tail defect

\begin{tabular}{|ccccc|}
\hline $\begin{array}{c}\text { Sperm } \\
\text { morphology }\end{array}$ & CONT+SED & CONT+EX & PCa+SED & PCa+EX \\
\hline N (\%) & $72.480 \pm 2.360$ & $43.650 \pm 3.780$ & $0.460 \pm 0.211^{* * * *}$ & $1.180 \pm 0.210^{* * * *}$ \\
\hline DH (\%) & $6.700 \pm 0.571$ & $15.550 \pm 4.520$ & $69.130 \pm 4.550^{* *}$ & $83.240 \pm 2.550^{* * * *}$ \\
\hline FH (\%) & $1.616 \pm 0.233$ & $0.926 \pm 0.166$ & $17.800 \pm 2.920^{* * *}$ & $11.690 \pm 2.100^{*}$ \\
\hline PH (\%) & $0.067 \pm 0.041$ & $0.030 \pm 0.028$ & $3.465 \pm 0.964^{* * *}$ & $0.319 \pm 0.135^{\# \#}$ \\
\hline BN (\%) & $8.542 \pm 1.930$ & $6.845 \pm 1.739$ & $4.158 \pm 0.847$ & $1.305 \pm 0.195^{* * *}$ \\
\hline TD (\%) & $10.630 \pm 1.380$ & $33.630 \pm 3.690$ & $4.800 \pm 1.729$ & $1.968 \pm 0.444^{*}$ \\
\hline & & vs. CONT+SED & vs. CONT+SED & $\begin{array}{c}* \text { vs. CONT+SED } \\
\text { \# vs. PCa+SED }\end{array}$ \\
\hline
\end{tabular}


Table 3 List of the differential expressed proteins and the respective fold change, corresponding to the main biological processes modulated in (according to STRING v10.5 and UniProt database): (a) CONT+EX when compared with CONT+SED; (b) PCa+SED when compared with CONT+SED; (c) PCa+EX when compared with CONT+SED $($ FDR $<0.05)$

\begin{tabular}{|c|c|c|c|c|c|c|c|c|c|}
\hline \multirow{3}{*}{$\begin{array}{c}\text { Biological } \\
\text { process }\end{array}$} & \multirow[b]{3}{*}{$\begin{array}{l}\text { Uniprot } \\
\text { ID }\end{array}$} & \multirow[b]{3}{*}{ Protein name } & \multirow[b]{3}{*}{$\begin{array}{l}\text { Gene } \\
\text { name }\end{array}$} & \multirow{2}{*}{\multicolumn{2}{|c|}{ a. CONT+EX }} & \multirow{2}{*}{\multicolumn{2}{|c|}{ b. PCa+SED }} & \multirow{2}{*}{\multicolumn{2}{|c|}{ c. PCa+EX }} \\
\hline & & & & & & & & & \\
\hline & & & & $\begin{array}{l}\text { Expre } \\
\text { ssion }\end{array}$ & $\begin{array}{l}\text { Fold } \\
\text { change }\end{array}$ & $\begin{array}{l}\text { Expre } \\
\text { ssion }\end{array}$ & $\begin{array}{l}\text { Fold } \\
\text { change }\end{array}$ & $\begin{array}{l}\text { Expre } \\
\text { ssion }\end{array}$ & $\begin{array}{l}\text { Fold } \\
\text { change }\end{array}$ \\
\hline \multirow{16}{*}{$\begin{array}{l}\text { Metabolic } \\
\text { processes }\end{array}$} & Q8VI04 & Isoaspartyl peptidase/L-asparaginase & Asrgl1 & - & - & $\downarrow$ & -1.3340 & $\downarrow$ & -1.5302 \\
\hline & P48500 & Triosephosphate isomerase & Tpi1 & - & - & $\downarrow$ & -1.0514 & $\downarrow$ & -0.7210 \\
\hline & D3ZDK7 & Glycerol-3-phosphate phosphatase & Pgp & - & - & $\downarrow$ & -1.0245 & $\downarrow$ & -0.6207 \\
\hline & P16617 & Phosphoglycerate kinase 1 & Pgk1 & _ & _ & $\downarrow$ & -0.8276 & $\downarrow$ & -0.7075 \\
\hline & 088767 & Protein/nucleic acid deglycase DJ-1 & Park7 & - & - & $\downarrow$ & -0.6270 & - & - \\
\hline & P24155 & Thimet oligopeptidase & Thop1 & - & - & $\downarrow$ & -0.6270 & $\downarrow$ & -0.4501 \\
\hline & Q64428 & $\begin{array}{l}\text { Trifunctional enzyme subunit alpha, } \\
\text { mitochondrial }\end{array}$ & Hadha & - & - & $\downarrow$ & -0.3650 & $\downarrow$ & -0.4185 \\
\hline & P19629 & L-lactate dehydrogenase $\mathrm{C}$ chain & Ldhc & - & - & $\downarrow$ & -0.3107 & $\downarrow$ & -0.3763 \\
\hline & P13437 & $\begin{array}{l}\text { 3-ketoacyl-CoA thiolase, } \\
\text { mitochondrial }\end{array}$ & Acaa2 & - & - & $\downarrow$ & -0.2724 & $\downarrow$ & -0.5846 \\
\hline & Q99NA5 & $\begin{array}{l}\text { Isocitrate dehydrogenase [NAD] } \\
\text { subunit alpha, mitochondrial }\end{array}$ & $\operatorname{ldh} 3 a$ & - & - & - & - & $\uparrow$ & 0.3013 \\
\hline & Q9Jப3 & $\begin{array}{c}\text { 4-trimethylaminobutyraldehyde } \\
\text { dehydrogenase }\end{array}$ & Aldh9a1 & - & - & $\uparrow$ & 0.3308 & - & - \\
\hline & O35567 & $\begin{array}{c}\text { Bifunctional purine biosynthesis } \\
\text { protein PURH }\end{array}$ & Atic & - & - & $\uparrow$ & 0.3941 & $\uparrow$ & 0.5748 \\
\hline & P09527 & Ras-related protein Rab-7a & Rab7a & _ & _ & $\uparrow$ & 0.4273 & $\uparrow$ & 0.6567 \\
\hline & P07943 & Aldose reductase & Akr1b1 & - & - & $\uparrow$ & 0.5083 & - & - \\
\hline & P10760 & Adenosylhomocysteinase & Ahcy & - & - & $\uparrow$ & 0.7490 & - & - \\
\hline & P50137 & Transketolase & Tkt & - & - & $\uparrow$ & 0.9039 & - & - \\
\hline \multirow{3}{*}{$\begin{array}{l}\text { Regulation } \\
\text { of cell death }\end{array}$} & P63039 & $\begin{array}{c}60 \mathrm{kDa} \text { heat shock protein, } \\
\text { mitochondrial }\end{array}$ & Hspd1 & - & - & $\uparrow$ & 0.2375 & $\uparrow$ & 0.2849 \\
\hline & P62909 & $40 \mathrm{~S}$ ribosomal protein $\mathrm{S} 3$ & Rps3 & - & - & $\uparrow$ & 0.3346 & - & - \\
\hline & P14668 & Annexin A5 & Anxa5 & _ & _ & $\uparrow$ & 0.3775 & _ & - \\
\hline
\end{tabular}




\begin{tabular}{|c|c|c|c|c|c|c|c|c|c|}
\hline & Q05962 & ADP/ATP translocase 1 & Slc25a4 & - & _ & $\uparrow$ & 0.4424 & - & - \\
\hline & Q07936 & Annexin A2 & Anxa2 & - & _- & $\uparrow$ & 0.6277 & $\uparrow$ & 0.5757 \\
\hline & P81155 & $\begin{array}{l}\text { Voltage-dependent anion-selective } \\
\text { channel protein } 2\end{array}$ & Vdac2 & - & - & $\uparrow$ & 0.7408 & - & - \\
\hline \multirow{4}{*}{$\begin{array}{l}\text { Oxidation- } \\
\text { reduction } \\
\text { process }\end{array}$} & Q6AY30 & $\begin{array}{c}\text { Saccharopine dehydrogenase-like } \\
\text { oxidoreductase }\end{array}$ & Sccpdh & - & - & $\downarrow$ & -0.4646 & $\downarrow$ & -0.6373 \\
\hline & P02793 & Ferritin light chain 1 & $\mathrm{Ft} / 1$ & - & - & - & - & $\uparrow$ & 1.1648 \\
\hline & Q920J4 & Thioredoxin-like protein 1 & Txnl1 & - & - & $\uparrow$ & 0.4248 & - & - \\
\hline & P13635 & Ceruloplasmin & $\mathrm{Cp}$ & - & - & $\uparrow$ & 0.5629 & - & - \\
\hline \multirow{2}{*}{$\begin{array}{l}\text { Regulation } \\
\text { of oxidative } \\
\text { stress }\end{array}$} & Q9Z1B2 & Glutathione S-transferase Mu 5 & Gstm5 & - & - & $\downarrow$ & -1.5337 & $\downarrow$ & -1.6170 \\
\hline & P36970 & $\begin{array}{l}\text { Phospholipid hydroperoxide } \\
\text { glutathione peroxidase }\end{array}$ & Gpx4 & - & - & $\downarrow$ & -1.2195 & $\downarrow$ & -1.1886 \\
\hline \multirow{9}{*}{$\begin{array}{l}\text { Spermatoge } \\
\text { nesis/Sperm } \\
\text { function }\end{array}$} & P31044 & $\begin{array}{l}\text { Phosphatidylethanolamine-binding } \\
\text { protein } 1\end{array}$ & Pebp1 & - & - & $\downarrow$ & -0.9629 & $\downarrow$ & -0.6960 \\
\hline & Q6MG49 & Large proline-rich protein BAG6 & Bag6 & _- & _ & $\downarrow$ & -0.8990 & $\downarrow$ & -0.5907 \\
\hline & Q5XI02 & $\begin{array}{c}\text { Protein disulfide-isomerase-like } \\
\text { protein of the testis }\end{array}$ & Pdilt & - & - & $\downarrow$ & -0.8206 & $\downarrow$ & -0.6689 \\
\hline & P63088 & $\begin{array}{c}\text { Serine/threonine-protein } \\
\text { phosphatase PP1-gamma catalytic } \\
\text { subunit }\end{array}$ & Ppp1cc & - & - & $\downarrow$ & -0.4542 & - & - \\
\hline & Q6P502 & T-complex protein 1 subunit gamma & Cct3 & - & - & $\downarrow$ & -0.2136 & $\downarrow$ & -0.2734 \\
\hline & P14659 & Heat shock-related $70 \mathrm{kDa}$ protein 2 & Hspa2 & - & _- & $\downarrow$ & -0.1831 & $\downarrow$ & -0.2650 \\
\hline & P55054 & Fatty acid-binding protein 9 & Fabp9 & - & - & - & - & $\downarrow$ & -0.7570 \\
\hline & P13383 & Nucleolin & $\mathrm{Ncl}$ & _- & _- & $\uparrow$ & 0.5168 & $\uparrow$ & 0.6858 \\
\hline & P05371 & Clusterin & Clu & - & - & $\uparrow$ & 0.5211 & $\uparrow$ & 0.3836 \\
\hline \multirow{5}{*}{$\begin{array}{l}\text { Response to } \\
\text { stress }\end{array}$} & P17475 & Alpha-1-antiproteinase & Serpina1 & - & - & $\uparrow$ & 0.3187 & - & - \\
\hline & P63259 & Actin, cytoplasmic 2 & Actg1 & - & _- & $\uparrow$ & 0.3187 & - & _- \\
\hline & P14046 & Alpha-1-inhibitor 3 & $\mathrm{~A} 1 \mathrm{i} 3$ & - & - & $\uparrow$ & 0.3336 & - & - \\
\hline & Q03626 & Murinoglobulin-1 & Mug1 & - & _- & $\uparrow$ & 0.4196 & - & _- \\
\hline & P12346 & Serotransferrin & Tf & - & - & $\uparrow$ & 0.5070 & _- & _ \\
\hline \multirow{2}{*}{$\begin{array}{l}\text { Regulation } \\
\text { of cell } \\
\text { proliferation }\end{array}$} & Q6IMY8 & $\begin{array}{l}\text { Heterogeneous nuclear } \\
\text { ribonucleoprotein } U\end{array}$ & Hnrnpu & - & - & - & - & $\uparrow$ & 0.5684 \\
\hline & Q9EST6 & $\begin{array}{c}\text { Acidic leucine-rich nuclear } \\
\text { phosphoprotein } 32 \text { family member B }\end{array}$ & Anp32b & - & - & $\uparrow$ & 0.7885 & $\uparrow$ & 0.9927 \\
\hline
\end{tabular}




\begin{tabular}{|c|c|c|c|c|c|c|c|c|c|}
\hline \multirow{2}{*}{ DNA repair } & 008629 & $\begin{array}{l}\text { Transcription intermediary factor } 1 \text { - } \\
\text { beta }\end{array}$ & Trim28 & - & - & - & - & $\uparrow$ & 0.4243 \\
\hline & P60123 & RuvB-like 1 & Ruvbl1 & - & - & - & - & $\uparrow$ & 0.7028 \\
\hline \multirow{2}{*}{ Translation } & Q68FR6 & Elongation factor 1-gamma & Eef1g & - & - & $\downarrow$ & -0.9426 & $\downarrow$ & -1.4948 \\
\hline & Q68FR9 & Elongation factor 1-delta & Eef1d & - & - & $\downarrow$ & -0.5527 & - & - \\
\hline \multirow{3}{*}{$\begin{array}{l}\text { Cellular } \\
\text { response to } \\
\text { stimulus }\end{array}$} & P61980 & $\begin{array}{l}\text { Heterogeneous nuclear } \\
\text { ribonucleoprotein } \mathrm{K}\end{array}$ & Hnrnpk & - & - & $\uparrow$ & 0.2500 & $\uparrow$ & 0.4131 \\
\hline & P34058 & Heat shock protein HSP 90-beta & $\begin{array}{l}\text { Hsp90ab } \\
1\end{array}$ & - & - & $\uparrow$ & 0.2977 & $\downarrow$ & -0.2240 \\
\hline & P63018 & Heat shock cognate 71 kDa protein & Hspa8 & - & - & $\uparrow$ & 0.4610 & $\uparrow$ & 0.3235 \\
\hline $\begin{array}{l}\text { Complement } \\
\text { activation }\end{array}$ & P01026 & Complement C3 & C3 & - & - & $\uparrow$ & 0.5761 & - & - \\
\hline $\begin{array}{c}\text { No } \\
\text { associations }\end{array}$ & P31000 & VImentin & Vim & $\uparrow$ & 0.9568 & - & - & - & - \\
\hline $\begin{array}{l}\text { Protein not } \\
\text { found in } \\
\text { STRING }\end{array}$ & P05544 & Serine protease inhibitor $\mathrm{A} 3 \mathrm{~L}$ & Serpina3l & $\uparrow$ & 0.7993 & - & - & - & - \\
\hline
\end{tabular}


Supplementary Table S1: The influence of prostate cancer (PCa) and exercise training (EX) on the incidence of non neoplastic and pre-neoplastic and neoplastic prostate lesions.

\begin{tabular}{|c|c|c|}
\hline \multirow{2}{*}{ Experimental group } & \multicolumn{2}{|c|}{ Type of lesions (\%) } \\
\cline { 2 - 3 } & Non neoplastic & $\begin{array}{c}\text { Pre-neoplastic and } \\
\text { neoplastic }\end{array}$ \\
\hline CONT+SED & 50 & 50 \\
\hline CONT+EX & 0 & 100 \\
\hline PCa+SED & 40 & 60 \\
\hline PCa+EX & 35 & 94 \\
\hline
\end{tabular}


Figure 1

a

b
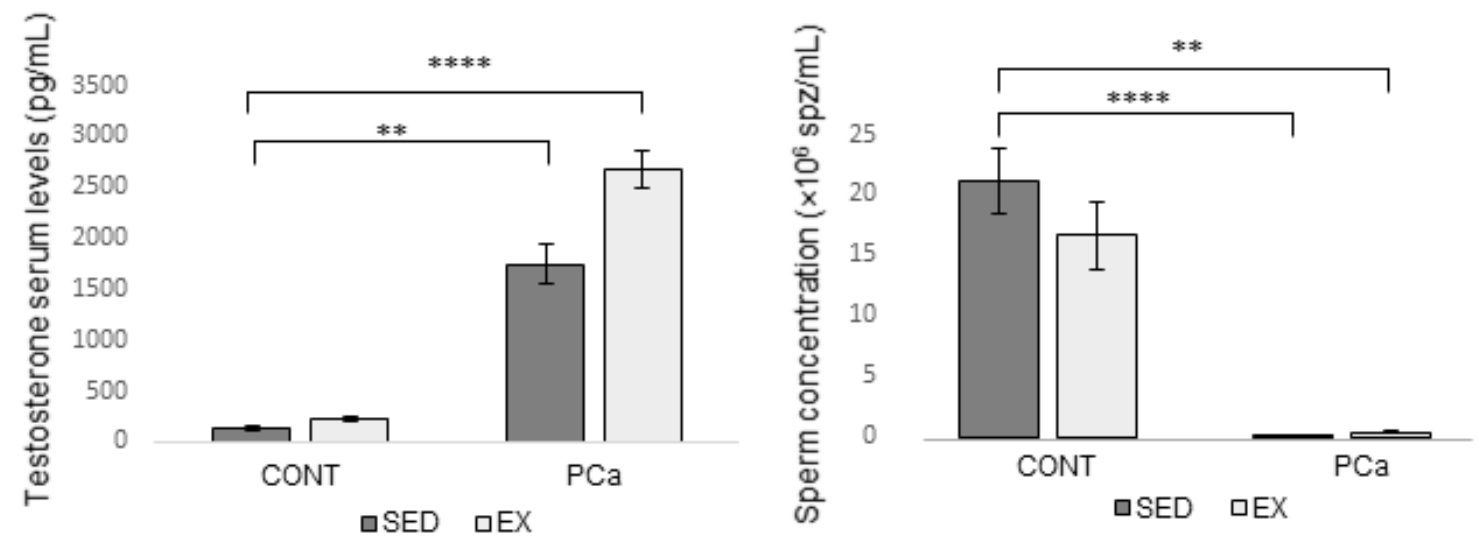

c

d

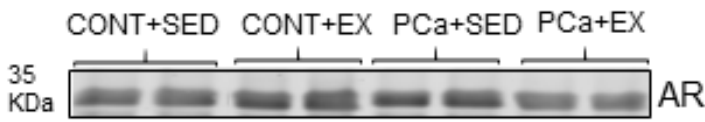

CONT+SED CONT+EX PCa+SED PCa+EX
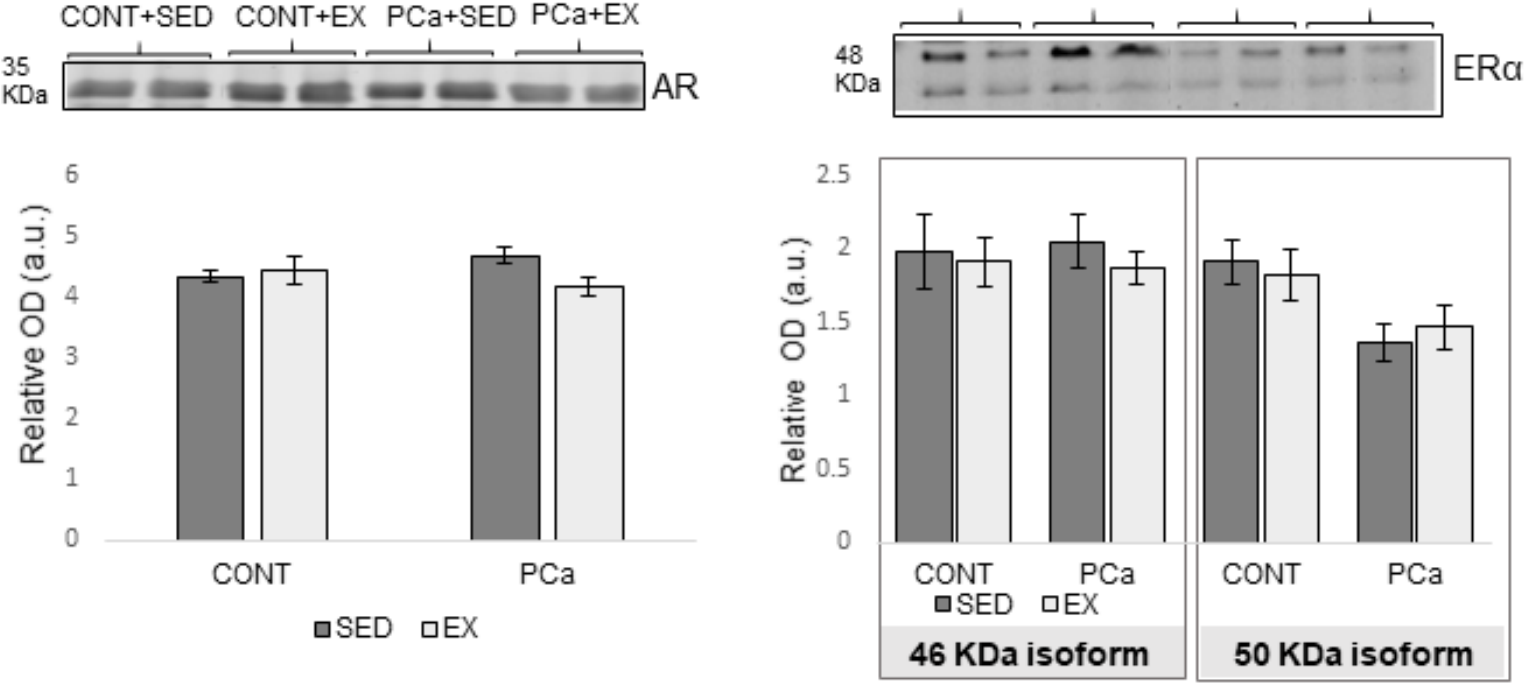
Figure 2
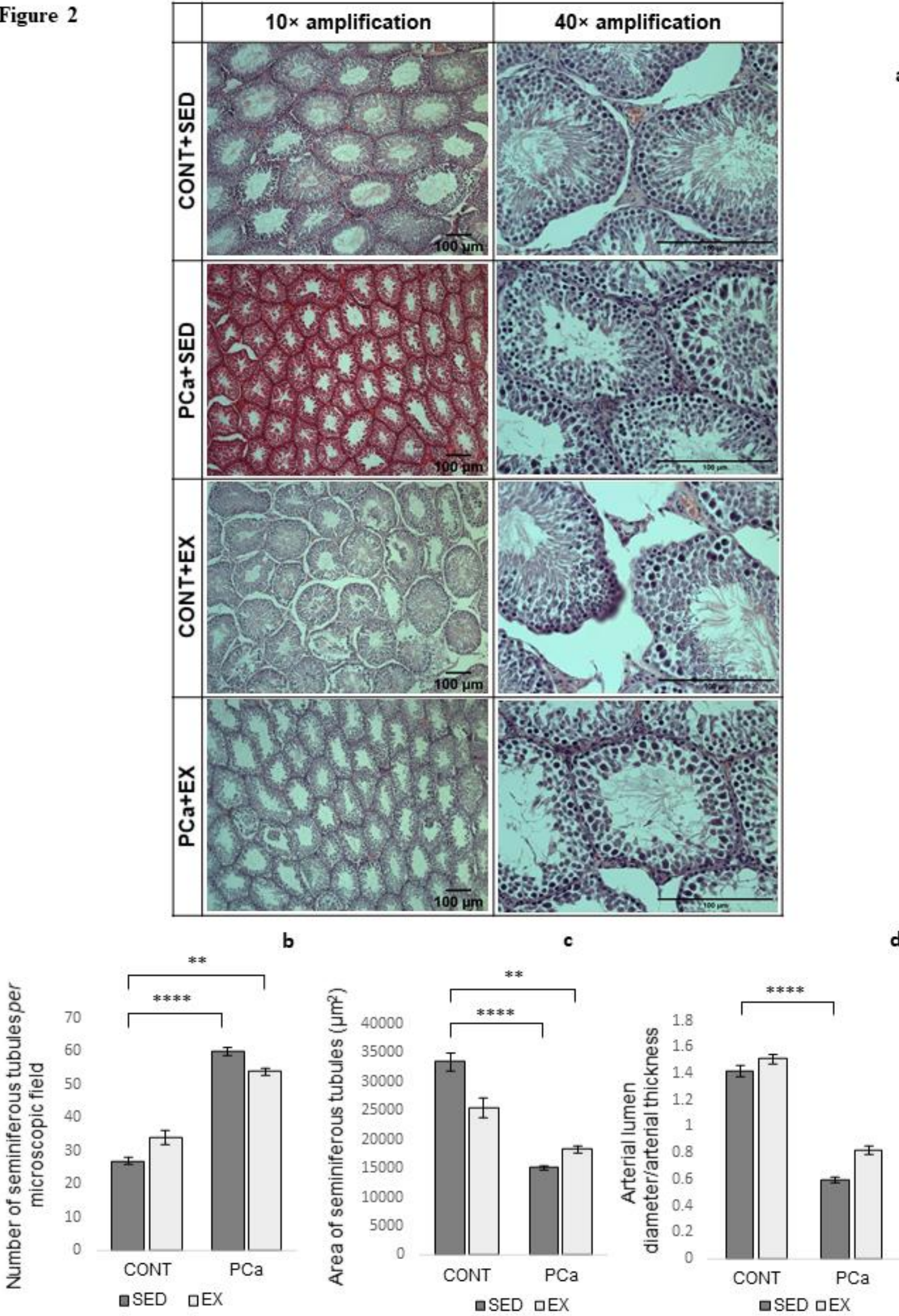
Figure 3
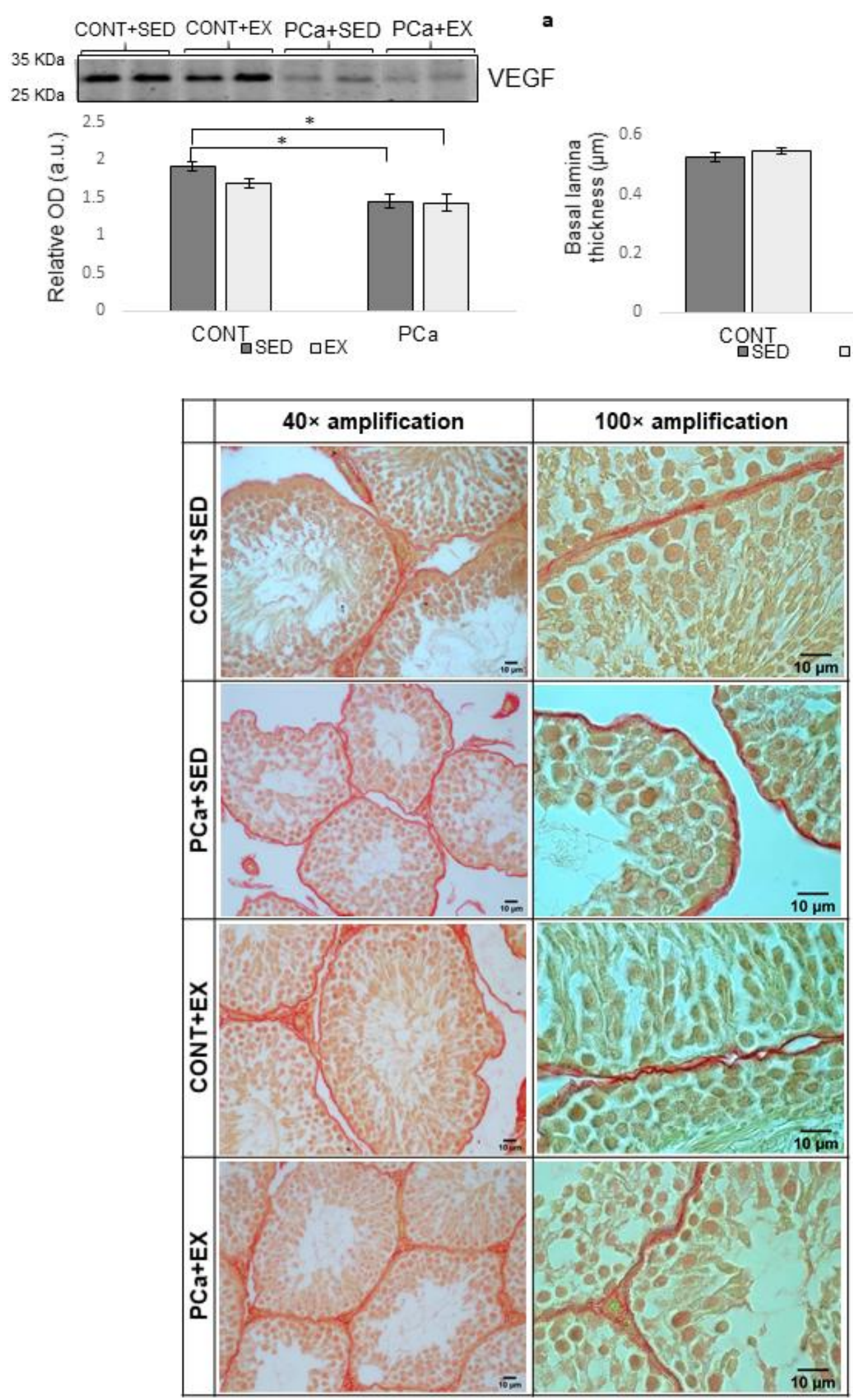
Figure 4

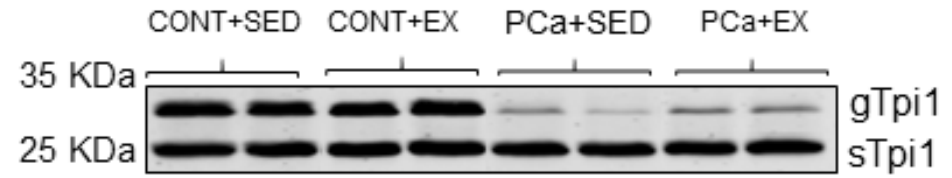

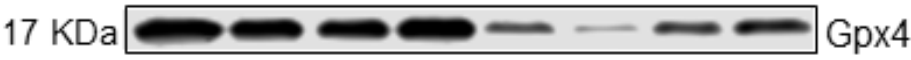
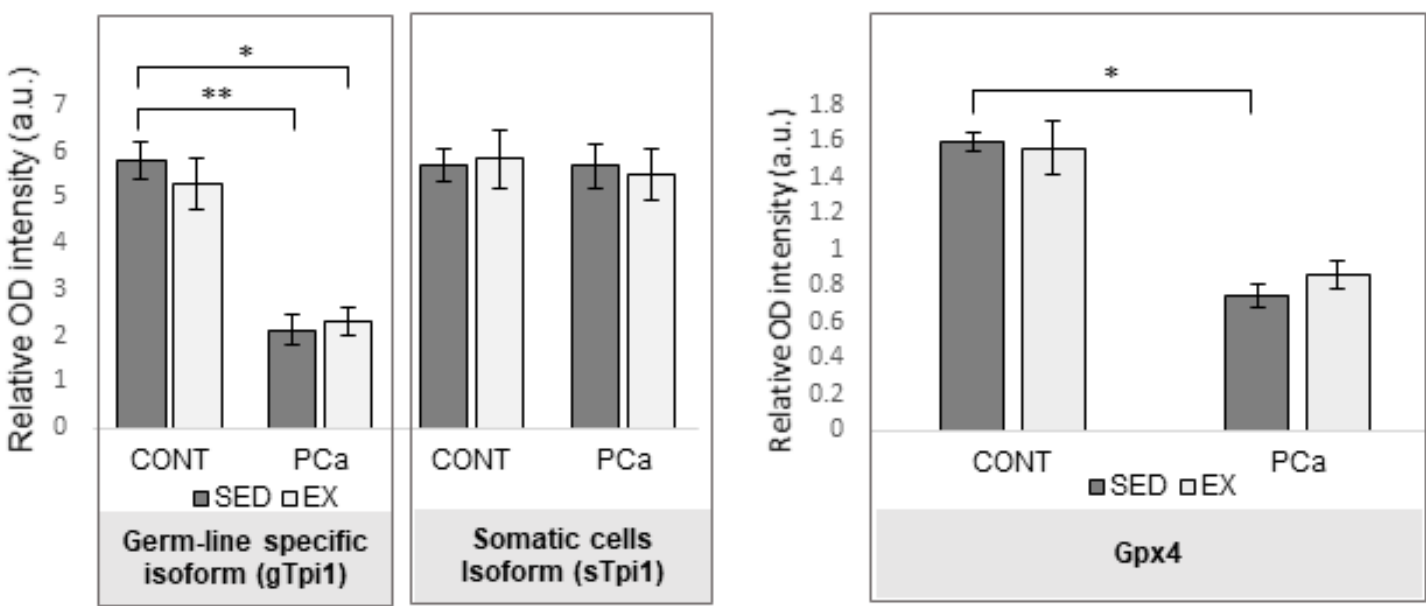
Figure 5

\begin{tabular}{|c|c|c|c|}
\hline & CONT+EX & PCa+SED & $\mathrm{PCa}+\mathrm{EX}$ \\
\hline M-inositol & & $* *$ & $* *$ \\
\hline Glucose & & $*$ & \\
\hline Tyrosine & & $* *$ & * \\
\hline Ethanolamine & & & $*$ \\
\hline Valine & & $* *$ & $* *$ \\
\hline Phosphoethanolamine & & $* *$ & $* *$ \\
\hline Isoleucine & $*$ & $* *$ & $* *$ \\
\hline Leucine & & $*$ & $*$ \\
\hline Aspartate & $*$ & & \\
\hline \multicolumn{4}{|l|}{ Uridine } \\
\hline Acetate & & $* *$ & \\
\hline Taurine & & $* *$ & $*$ \\
\hline Ascorbate & & $*$ & \\
\hline Creatine & & $* *$ & $* *$ \\
\hline Adenosine & & $* *$ & $* *$ \\
\hline Glutamate & & $* *$ & $* *$ \\
\hline Alanine & & $* *$ & * \\
\hline UDP-glucose & & & $* *$ \\
\hline Succinate & & * & 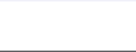 \\
\hline GSH & & $* *$ & $* *$ \\
\hline Glycerophosphocholine & & $* *$ & $* *$ \\
\hline Glycerol & $* *$ & $* *$ & $* *$ \\
\hline Betaine & & $* *$ & $* *$ \\
\hline$\beta$-hydroxybutyrate & & * & * \\
\hline
\end{tabular}


Figure 6

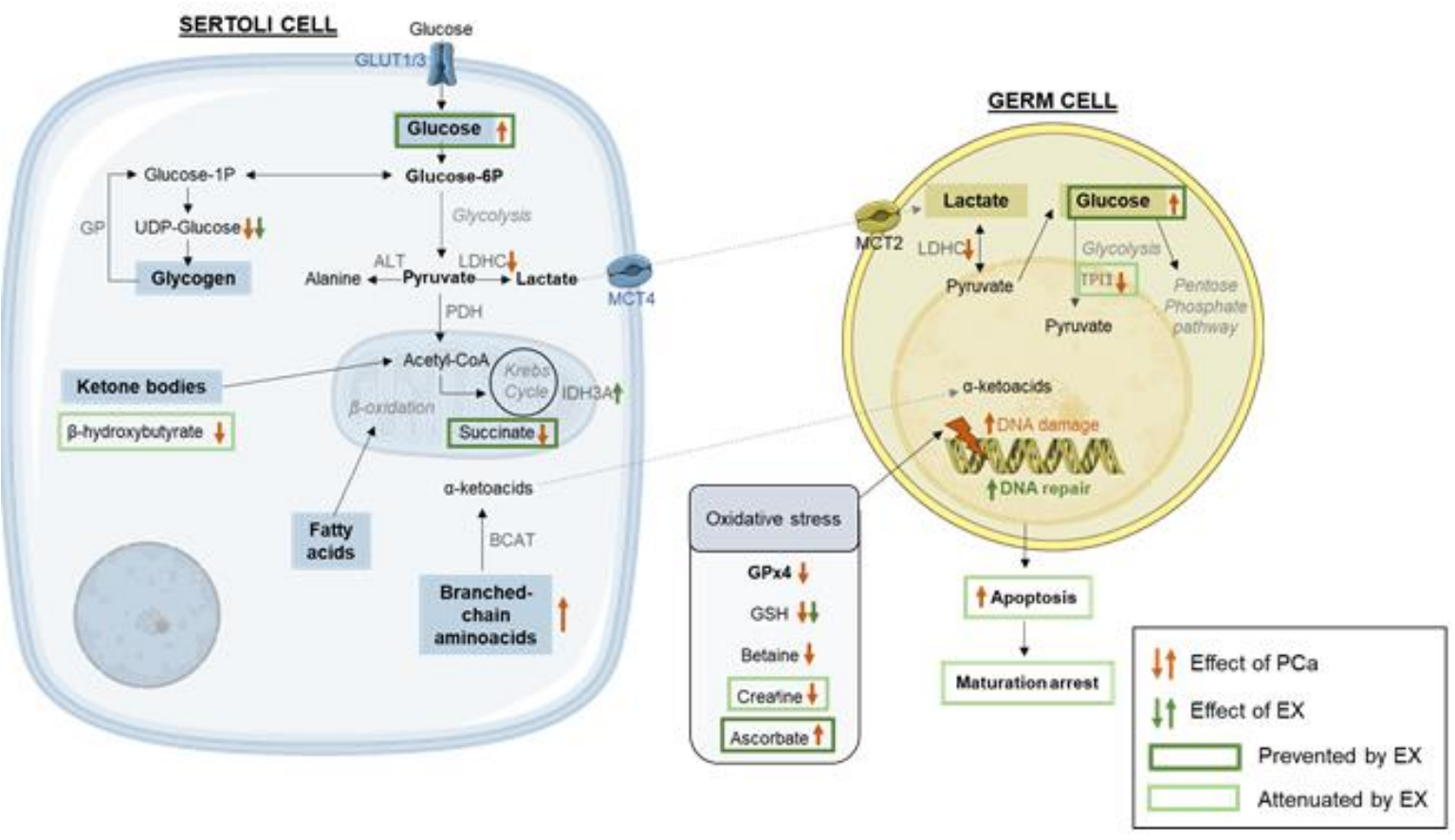




\section{Supplementary Figure S1}

b
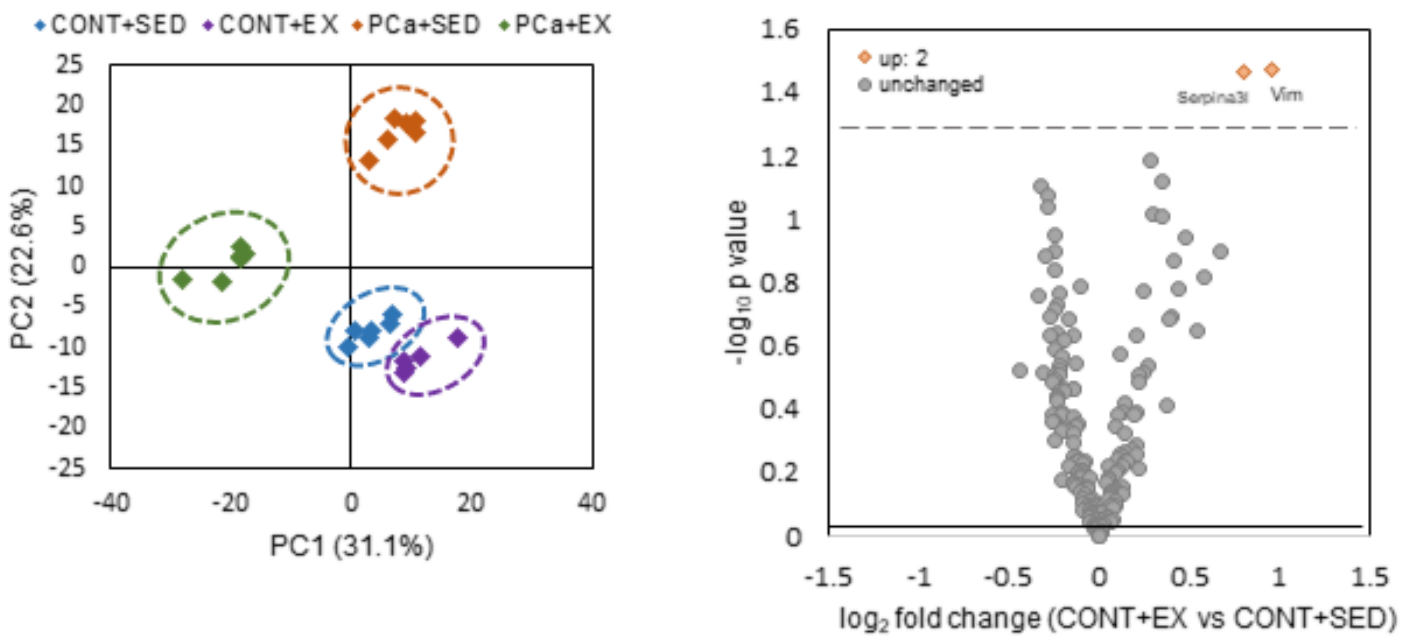

c

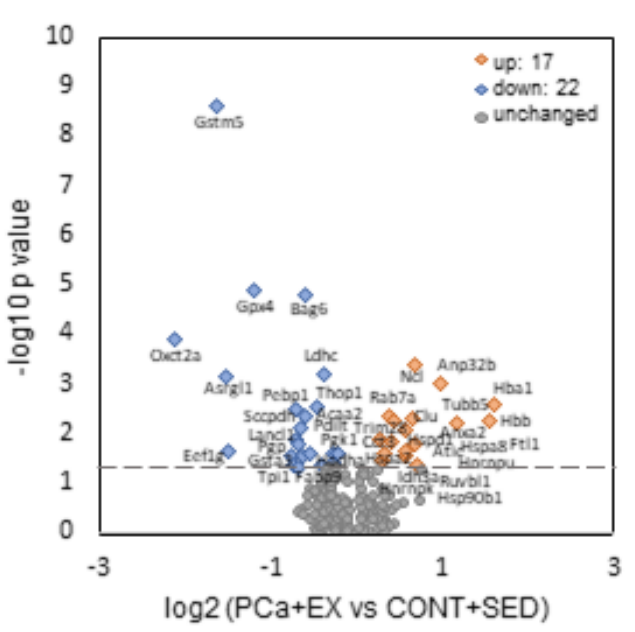

d

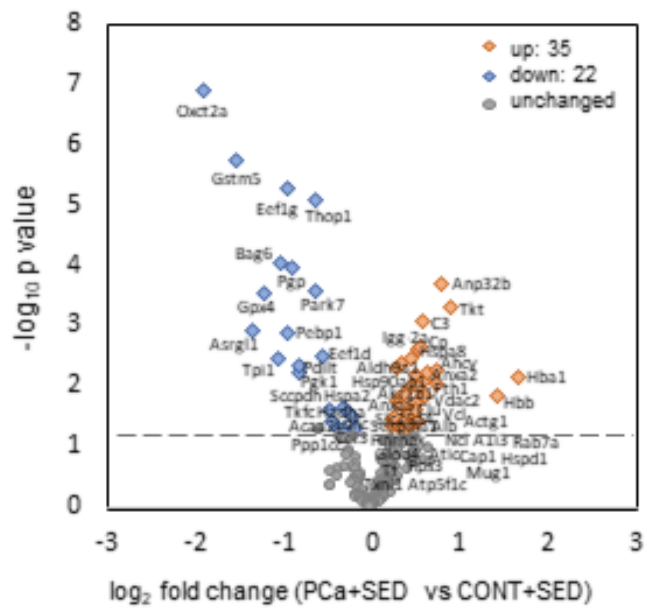

$$
\text { D) }
$$


Supplementary Figure S2 * CONT+SED * CONT+EX • PCa+SED * PCa+EX
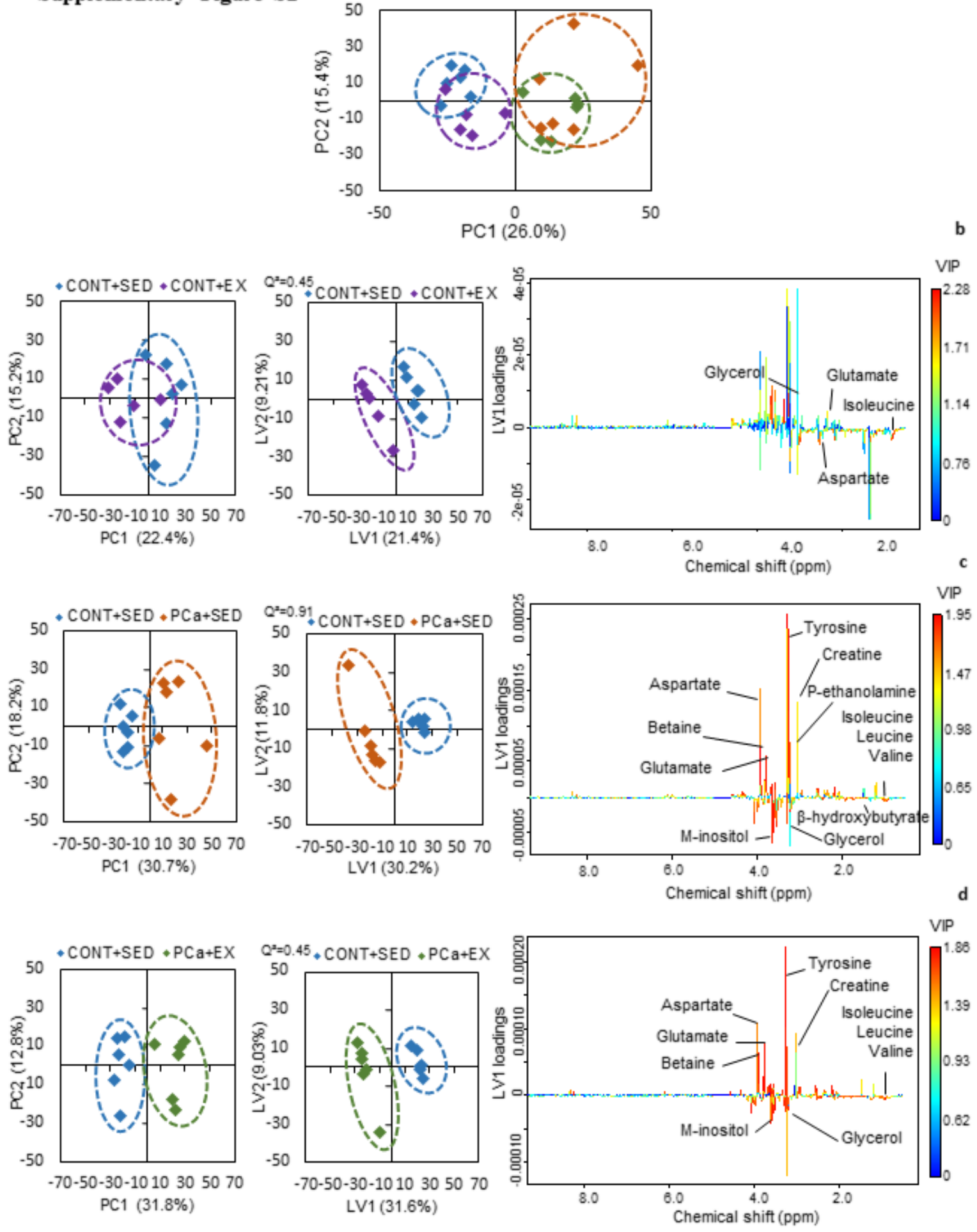